This document is the accepted manuscript version of the following article:

waser, L. T., Boesch, R., Wang, Z., \& Ginzler, C. (2017). Towards automated forest mapping. In T. K. Remmel \& A. H. Perera (Eds.), Mapping forest landscape patterns (pp. 263-304). https://doi.org/10.1007/978-1-4939-7331-6_7

\section{Towards Automated Forest Mapping}

Lars T. Waser, Ruedi Boesch, Zuyuan Wang and Christian Ginzler

Swiss Federal Institute for Forest, Snow and Landscape Research, Zuercherstrasse 111, CH-8903

Birmensdorf, SWITZERLAND

(waser@wsl.ch)

The need for up-to-date and accurate information on forest resources has rapidly increased in recent years. Forest mapping is an important source of information for the assessment of woodland resources and a key issue for any National Forest Inventory (NFI). Nowadays, new perspectives for automated forest mapping are emerging through the latest developments in remote sensing data and techniques. In this chapter, an overview of current remote sensing data and techniques for mapping woodland and forests, the challenges and requirements for optimization and automation, and the need for validating final products are presented. Special attention is paid to land use - a crucial criterion for forest mapping which, in contrast to land cover, cannot be easily derived from remotely sensed data. Three different approaches for extracting woodland areas (i.e., patches of trees and shrubs) are presented, all of which involve a high degree of automation. Two additional approaches, which are based on NFI forest definitions, are presented. These require the subdivision of woodlands into the classes "used for forestry" and "other use" and implement the criteria "height", "minimum crown coverage", "minimum area" and "minimum width", and land use. Special attention is paid to connecting patches using distance criteria from national forest definitions.

The main points of this chapter are: (1) forest needs an exact definition which may differ depending on the country, (2) mapping woodland can be highly automated and is indispensable prior to mapping forests, and (3) forest mapping is now feasible using remote sensing data and techniques, however, it is less automated due to the implementation of a forest definition.

Keywords: remote sensing, 3D point clouds, tree extraction, forest parameters

Glossary:

Airborne Laser Scanning (ALS)

Canopy Height Model (CHM)

Color-Infrared (CIR)

Digital Terrain Model (DTM) 
Digital Surface Model (DSM),

34 Generalized Linear Model (GLM)

35 Ground Sample Distance (GSD)

36 Individual Tree Crowns (ITC)

37 Interpretation Plot (IP)

38 International Geosphere Biosphere Program (IGBP)

39 K-Nearest Neighbor (k-NN)

40 Light Detection and Ranging (LiDAR)

41 National Forest Inventory (NFI)

42 Normalized Difference Vegetation Index (NDVI)

43 Reducing Emissions from Deforestation and Degradation (REDD)

44 Synthetic Aperture Radar (SAR)

45 Trees Outside Forest (TOF)

46 Vegetation Height Model (VHM)

47 Very High Resolution (VHR)

\section{Introduction}

This chapter is organized into four main sections: 1) the requirements for automated forest mapping 51 regarding forest definitions, remote sensing data sets and techniques, and existing maps, 2) commonly 52 used data sources and processing techniques, 3) three highly automated approaches for woodland 53 mapping, and 4) two highly automated approaches for forest mapping. The content of each section is 54 briefly summarized.

$55 \quad$ Forest mapping is a critical task because the resulting datasets are fundamental input for a broad range of users and applications, ranging from global environmental change assessment to local forest 57 management planning (see, for example, the Modelling Wildfire Regimes, and Mapping Insect

58 defoliation chapters in this volume). Precise, up-to-date, and regularly gathered information on the 59 area covered by trees and shrubs is an important basis for assessing woodland resources and 60 understanding the functionality of forests.

61 The need for consistency and the reduction of manual workload are key reasons for automation in 62 forest mapping. Thus, a high degree of automation in the process of assessing woodland is essential for 63 governmental authorities, international reporting (including the Kyoto protocol), activities within the 
Reducing Emissions from Deforestation and Degradation (REDD) framework, forest disturbance 65 assessments, and biodiversity and restoration programs. Based on mapped woodland, other forest66 related parameters (e.g., forest structure, biomass, and carbon storage) are estimated, which are, in 67 turn, needed for resource management by public and private authorities.

One particular challenge to forest mapping is the fact that the term forest is often defined similarly to woodland by the remote sensing community. In most studies, a simplified and generalized definition for forest is applied, which is mainly based on minimal tree height, minimal tree area, and width and crown coverage, and less on land use according to National Forest Inventories (NFI)s. Thus, besides the availability, processing, and quality of remotely sensed data, in order to map forest, an appropriate definition of forest must be applied. The need to clarify the difference between woodland and the varying definitions of the term forest is highlighted below.

\section{Definitions}

The goal of this section is to emphasize the difference between woodland, trees, and forests since a variety of forest-related terms and a wide range of forest definitions exist. Prior to defining the term forest, however, a short explanation of the difference between land cover and land use should be given, since the criteria used to define forests are usually based on their definitions or sometimes a combination of them. Problems arise regarding land use, which, while a key parameter in the NFI definition of forest, is nor easily assessable when using remotely sensed data-in contrast to land cover which is assessable.

Usually, land cover is distinct from land use, despite the two terms often being used interchangeably. In short, land cover indicates the physical land type, whereas land use indicates how people are using the land. For example, a temporarily un-stocked area (e.g., after impacts such as fires, storms, or harvesting) will be identified as a non-forest land cover type when using remote sensing data and techniques, but will in fact maintain its status as a forest land use type within the NFI. According to the Food and Agriculture Organization (FAO) (FAO 1997) land cover refers to the physical forms of land cover observable from airborne and spaceborne remote sensing data, and to their structure. It includes vegetation (e.g. grassland and trees) which may be natural or planted, and non-vegetated areas (e.g. bare ground, asphalt, and water). One of the major land cover issues is that similarly named categories are often defined in different ways (Alford 1993). For example, areas without trees may be classified as forest if the intention is to re-plant (such as in the UK and Ireland), and areas with many trees may not be labeled as forests if the trees are not growing fast enough (such as in Norway and Finland). 
Land use refers to the function of land and how it is used by people, that is, the activities undertaken on it to produce goods and services. Land use is characterized by the arrangements, activities, and inputs people undertake within a certain land cover type to produce, change or maintain the land. Many land use classification systems and programs have been developed worldwide. The most commonly used terms in use include urban, agricultural, forest, water, and wetlands (FAO/UNEP 1999). A good overview and more details may be found in Fisher et al. (2005).

102

103

Forest

Even though a precise and unambiguous definition of forest is indispensable when mapping and 105 comparing forest areas, this is frequently neglected by using a simplified term woodland (Fig. 1). This term can be used to include both trees and shrubs and is one of the most important parameters in forestry. In most NFI, the estimation of forest cover is a crucial parameter and should therefore be easily understood and reproducible. NFI programs are required to produce timely and accurate estimates for a wide range of forest resource variables for a variety of users and applications. They aim to periodically report the current state of and changes in forests by providing quantitative statistical information on area, species composition, volume, and growing stock. Clearly, the definition of forest is also crucial to assess areas of deforestation which refer to areas where a forest has formerly been. Using exactly the same unambiguous definitions of forest over time is essential - otherwise, the stated deforestation cannot be properly understood.

The term forest always implies a definition (usually the percentage of area covered by trees, with a minimum area and tree height) - although the commonly used terms stocked area, tree area or area covered by trees are often handled in a similar manner. To classify an area as forest or as non-forest, different forest definitions are available which should be defined based on exact geometric terms. Unfortunately, current definitions of forest are imprecise in most cases. Differing from country to country, a standardized and generally valid definition is non-existent, since the term forest can be defined according to different criteria. Moreover, the definition of forest varies depending on the context. For example, there may be differences from a silvicultural, ecological, or legal point of view. According to Lund (2016), over 960 forest definitions exist worldwide, while the minimum thresholds for degree of tree cover in these definitions vary between $5 \%$ and $80 \%$.

The FAO of the United Nations has defined forest as lands which are larger than 0.5 hectares in area, with a tree cover of more than $10 \%$ (FAO 2000, 2001, 2010). In most national and global forest 
definitions, the key parameters defining forest are height, width or area, and crown coverage. According to Tomppo et al. (2010), tree cover thresholds for forest definition in NFIs range from $10 \%$ to $50 \%$ among different national definitions. For example, this threshold is $10 \%$ for France and Scandinavian countries, 20\% for Great Britain, Spain and Switzerland, 25\% for the United States, rising to 30\% for Austria and New Zealand, and 50\% in Germany and Hungary. Even on a national level, forest is often defined differently by various authoritative bodies within individual countries. Despite the fact that these measurable items describe land cover, land use cannot be easily calculated out of measurable data. Even in the field, the main use of trees is difficult to determine. Deciding whether extensively used fruit trees, olive trees, or Christmas tree plantations close to a forest's edges belong to forestry land or not is highly subjective.

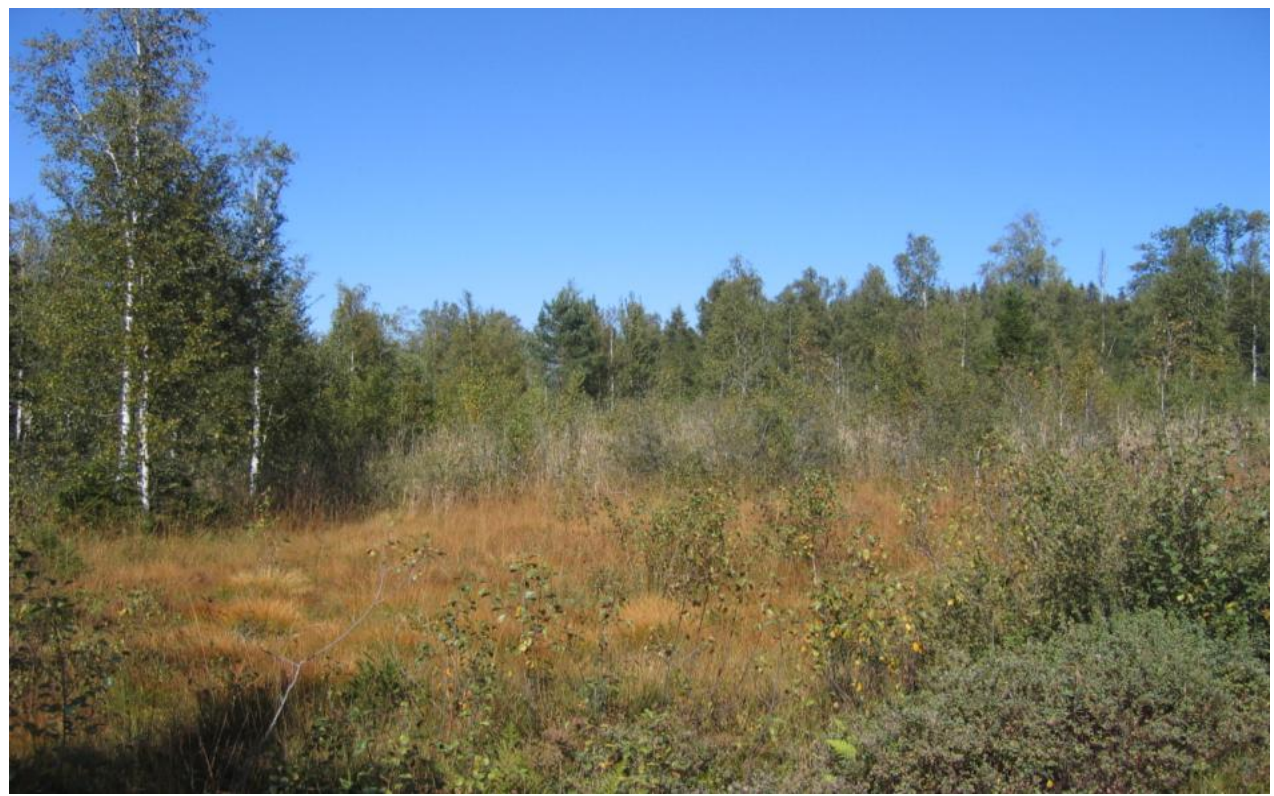

Figure 1. Woodland in the temporal zone of Switzerland consisting of individual trees and shrubs of different ages may belong to a forest or not - depending on the definition of forest used.

\section{Remote sensing for automated mapping of woodland and forest}

Remote sensing used in the forestry sector covers a wide variety of techniques and applications for extracting woodland, and while some have been operational for decades, others have only appeared recently and are undergoing fast development (Koch et al. 2008). Providing consistent, reproducible and up-to-date information on various forest parameters proves to be the main advantage of using remote sensing as a tool for monitoring, for example, in the framework of NFIs, and for mapping purposes, for instance, in national map products. 
Traditionally, woodland mapping approaches have been the product of visual image interpretations and delineation of aerial imagery in combination with field visits. Thus, their development is time consuming, and restricted to relatively small areas. In addition, shadow effects limit the exact detection of forest borders or small gaps.

In the two last decades, NFI data has been combined with remote sensing data and techniques (Tomppo et al. 2008, McRoberts et al. 2014) to map forest precisely. This has been achieved mostly by extrapolating estimates from field plot samples using the k-nearest neighbor (k-NN) algorithm (Tomppo and Halme 2004). A good overview of remote sensing support for NFIs can be found in McRoberts and Tomppo (2007) and Barrett et al. (2016). While visual image interpretation is quite time consuming and more subjective-which, depending on the experience of the interpreter, may be appropriate for small area applications-mapping woodland based on entire satellite images is feasible with high accuracy within short timeframes thanks to highly automated approaches. Existing remote sensing-based forest maps vary in scale (global, continental, pan-European, and national levels), and also in the level of detail (sources of information, forest definition, and target interest groups). While forest stand maps provide very detailed information, forest layers of map products are much more generalized, with scales ranging from a few meters up to $1 \mathrm{~km}$. How accurate and up to date the maps are may vary in both products due to coarse image resolution and a certain time gap between image acquisition and production. Consequently, forest borders, gaps, and areas with close dense forest may not be sufficiently represented to a large degree.

Over the last decade, many at least partly automated forest mapping approaches have been implemented based on remote sensing techniques and data in the framework of research case studies, national forest inventories, and mapping or resource assessment programs. Highly automated mapping approaches that are mostly restricted to relatively small areas have been used in the framework of change detection studies in general (Waser et al. 2008a, Wang et al. 2015), FAO forest definition applications (Magdon et al. 2014), and the assessment of deforestation such as REDD (Gebhardt et al. 2014). Recently, Waser et al. (2015) presented a wall-to-wall forest mapping approach for all of Switzerland incorporating the NFI forest definition.

At the global scale, particularly worth mentioning are the Global Forest Resources Assessment Remote Sensing Survey (FAO 2012) initiated by the Food and Agriculture Organization (FAO), the Global Forest Watch (GFW) (GFW 2016) initiative of the World Resources Institute, the Global Land Cover mapping approach (GLC) (Bartholomé \& Belward 2005), the global forest/non-forest mapping initiated by the Japan Aerospace Exploration Agency (JAXA 2016), and the European 2006 Forest cover map (JRC 
2016) from the Joint Research Center (JRC). Recently, Hansen et al. (2013) generated a spatially and temporally detailed global forest and forest change map, which provides valuable information for many land use related applications at the regional level. More recently, Schepaschenko et al. (2015) presented a global hybrid forest map approach based on remote sensing data, maps, and FAO statistics, and new global forest/non-forest maps based on ALOS PALSAR data (2007-2010) were developed by Shimada et al. (2014).

\section{Data and Pre-processing}

In this section, we review the current state of research and technology required for automated mapping of woodland and forest.

\section{Reference data}

Satellite imagery, large mosaics of aerial imagery or a combination of both have become wellaccepted sources of landscape information that contribute to the construction of land cover maps. While forest maps are constructed using such images, forest inventory data or derivatives often come from other existing maps. However, these maps are not always sufficiently validated for various reasons. Often, no adequate reference data is available to evaluate maps. The need for reference data and accurate assessment tools for maps that distinguish between the three land cover classes of non-forest, coniferous forest, and deciduous forest is raised in McRoberts (2012). The minimum requirements of reference data sets commonly used for evaluating woodland and forest maps are given in this section. An adequate reference data set can be characterized by the following traits:

- minimal time span between acquisition of reference data and data the mapping is based on

- $\quad$ minimal differences between the reference data and mapping scales

- $\quad$ reproducibility (by different users)

- reliable data source (e.g. from inventory data or field measurements - and not digitized from existing map products)

- representative of the area under investigation (size, dispersion)

The collection of reference data remains time consuming and is the least automated step in the implementation of any mapping approach. In the following sections, examples of practicable and reliable (best practice) reference data sets with pros and cons are presented: 
212 In these data sets, acquisition is carried out at the individual tree level and suitable for fine-scale 213 applications and small areas (a few to a few dozen square kilometers), for instance, at stand, local or 214 community levels. In order to be representative of trees within an area of interest, different types of 215 randomly sampled digitized polygons such as tree crowns or crown clusters that belong to entire tree 216 groups anywhere in the woodland-preferably at borders, and in open land as single trees-should be 217 considered. The delineation can be carried out either by digitizing polygons of tree crowns on 218 orthorectified aerial images, or by stereo-interpretation of aerial images. While both methods of 219 collecting reference data can be regarded as very effective-depending on the pre-knowledge and 220 expertise of the interpreter and time availability-the latter depends on the extent of the area to be 221 investigated. Figure 2 shows examples of these different types of tree and non-tree polygons, which 222 were digitized on true color orthoimages in a study area in Switzerland. While a certain degree of 223 experience is needed on the part of the interpreter, little technical or forest-related knowledge is 224 required. The collected reference data is reliable and reproducible. Depending on the area under 225 investigation, the manual workload can increase rapidly. 


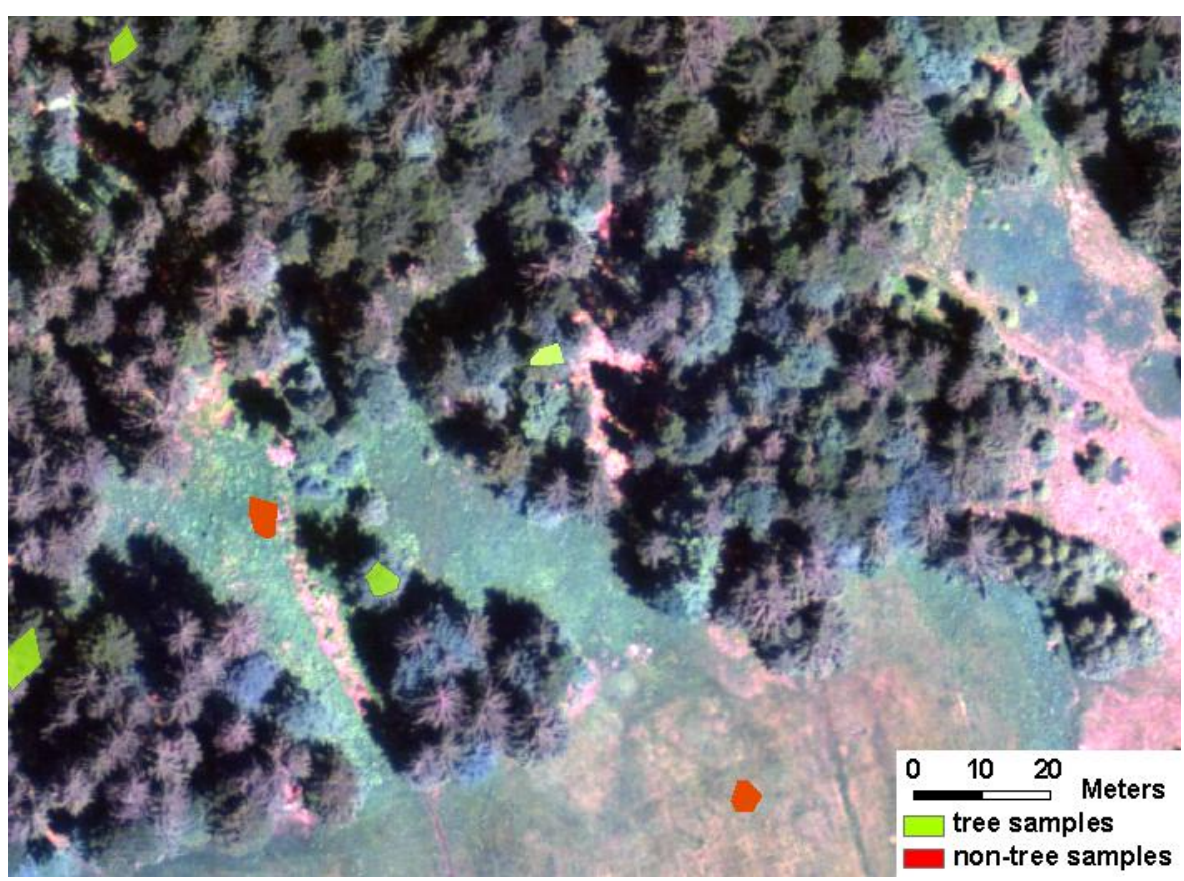

229

230

231

232

233

234

235

236

237

238

239

Figure 2. Examples of digitized tree and non-tree polygons based on a true color orthoimage in a mixed temperate forest in Switzerland.

\section{Regular point raster}

Tree/non-tree decisions at each grid point in a regular point raster is another very effective method for validating mapped woodland or forest. The regular point raster can either cover the entire area of interest or consist of a limited number of regular points at the edges of a regular grid with a larger mesh size. The optimal mesh size depends on the required level of detail, the area of interest, and the time resources available. If the interpretation is based on stereo-images, the regular grid must be extracted from the digital surface model (DSM) - the same one used for the orthoimage generation. A raster point is assigned as non-tree if the cursor is on the ground or within a shadow on the ground. Problems may occur with areas that have shadows if it is not clear where the exact position of the cursor is set. In these cases, each point must be handled consistently for the entire area of investigation, regardless of the assignment decision. In practice, a 10-50 m mesh size is generally most appropriate for small areas of few square kilometers, and up to $500 \mathrm{~m}$ for large areas of several thousand square kilometers. Figure 3 shows an example of aerial image-interpreted tree/non-tree decisions based on a $10 \mathrm{~m}$ regular point grid.

The interpreter's requirements for this approach are similar to that needed for the digitized polygons for which little technical and forest-related knowledge is required. Again, the collected reference data is 
249 workload can increase rapidly.

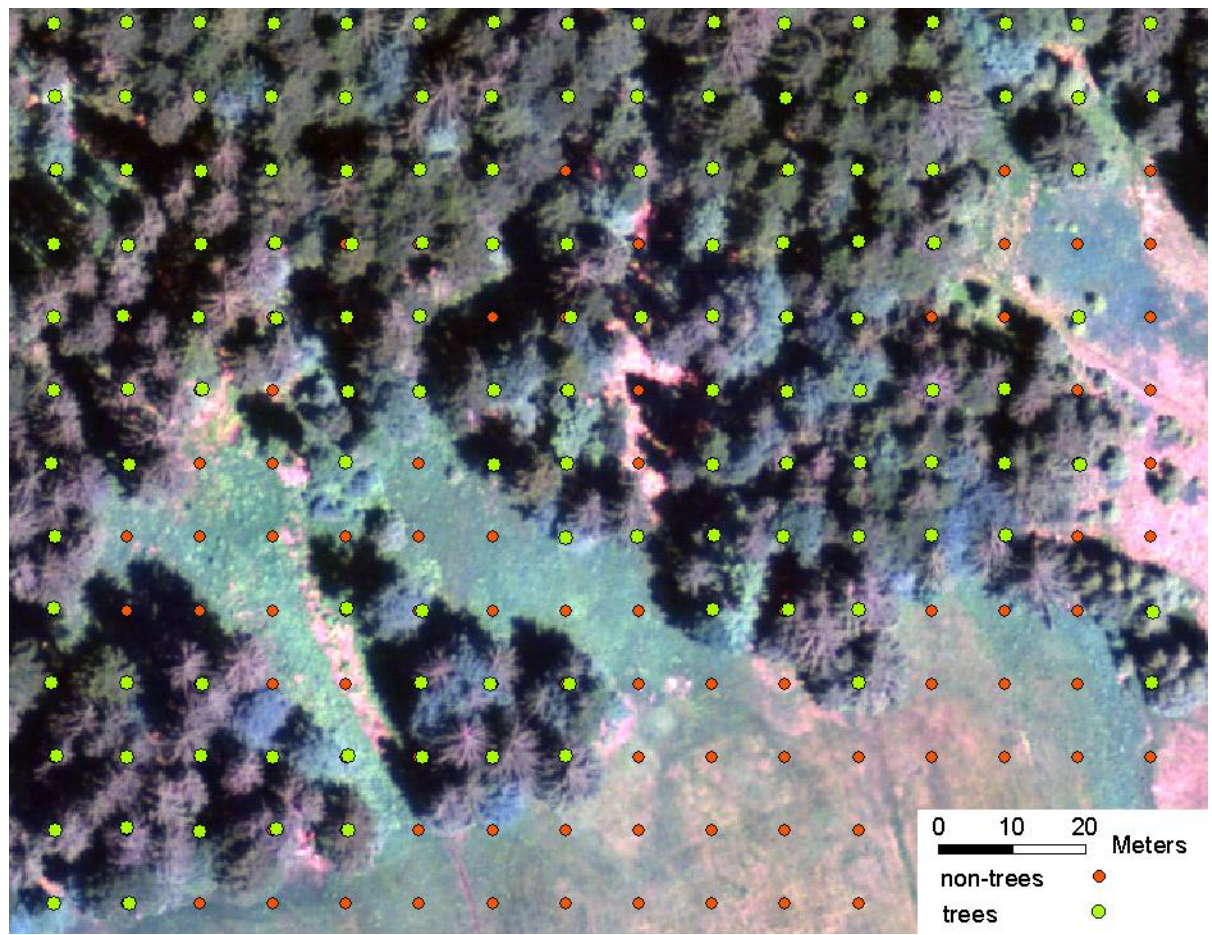

251 Figure 3. True color aerial image-interpreted point raster for the same area with tree/non-tree decisions. The grid has a spacing of $10 \mathrm{~m}$ and shadows on the ground are assigned as non-trees.

Another example of the regular point raster approach is the stereo-image interpretation of NFI plots, 254 which usually use a much larger mesh size (see Figure 4). 


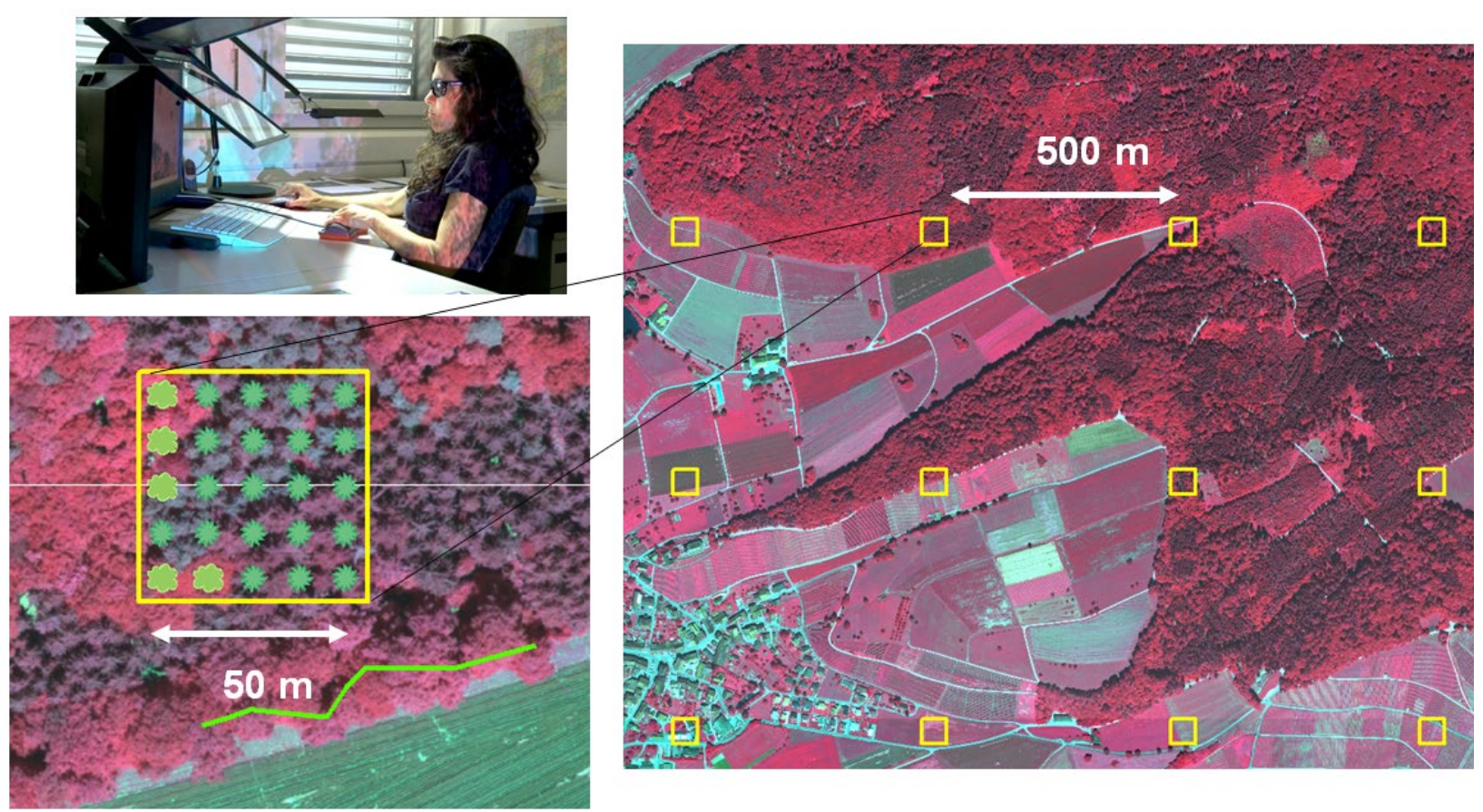

Figure 4: Stereo-interpretation of 25 points of a regular raster for tree/non-tree decisions and the distinction between deciduous (flowers) and coniferous trees (stars) on a false color-infrared aerial image (left). The grid has a spacing of $5 \mathrm{~m}$ and is part of the $500 \mathrm{~m}$ regular raster for stereo-interpretation in the framework of the Swiss NFI (right).

\section{External data sets}

Another method is to use external data sets to validate mapped woodlands or forest, either from existing forest-related data sets such as stand maps and tree cover maps, or from side products, such as layers from any kind of available map (thematic and topographic). The latter are often produced in a context different from forestry. Examples include forest border delineation or the identification of forest areas for layers in topographic maps or for layers in thematic maps, such as land cover/land use vegetation maps or maps from CORINE provided by the European Environmental Agency's International Geosphere Biosphere Program (IGBP - an international research program that studies the phenomenon of global change). The disadvantages of using such data sets are manifold. Issues of concern include data set up-to-dateness (they are often old and rarely updated regularly), and the fact that, as side products, they tend to be less accurate and less detailed than digitized polygons or raster points. An example of delineated forest borders identified as a side product within the framework of a project-which aimed at updating the measurement of agricultural area to match registered cadastral surveying in Switzerland - is illustrated in Figure 5. 


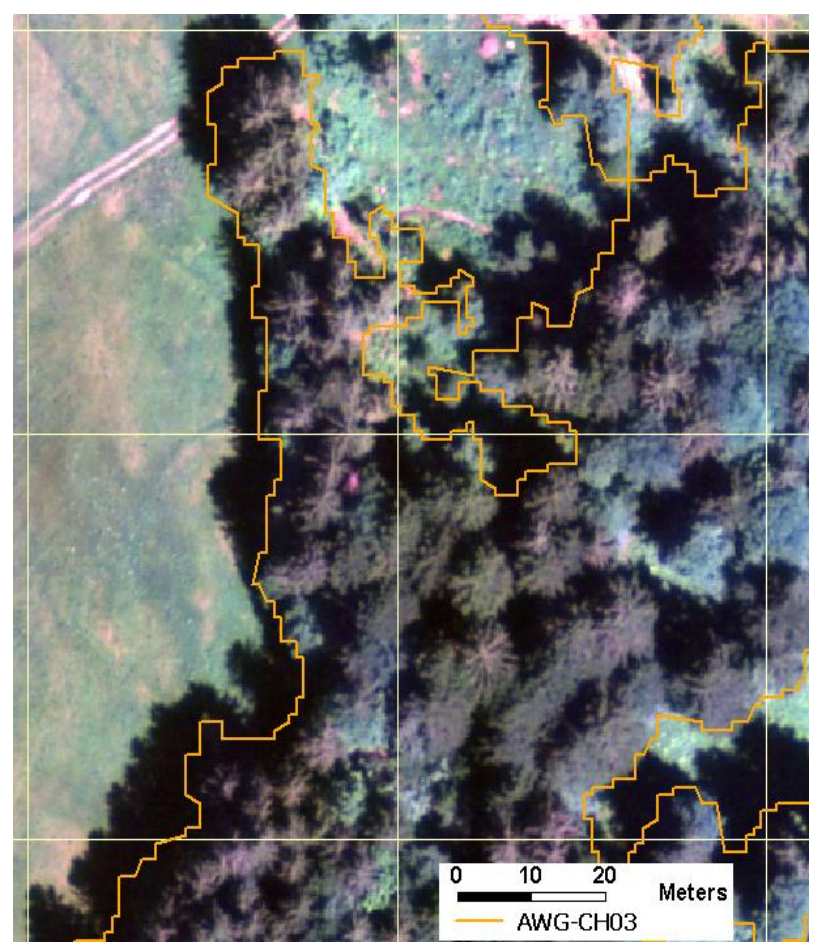

276 Figure 5. Forest border delineation (yellow line) based on a LiDAR vegetation height model. Large forest 277 gaps are well represented in the true color aerial image, whereas smaller strips of trees or gaps may not be entirely detected.

\section{Remote sensing systems}

Before giving an overview of existing remote sensing systems, we first provide a short explanation of passive/active systems and their history in the context of mapping woodland areas. Passive sensor systems measure energy wavelengths of the electromagnetic spectrum that are reflected or emitted by objects on the earth's surface. Active sensor systems send out energy, in waves or pulses, in the direction of interest and record the energy coming back from the surface. One advantage in favor of active sensors is the ability to obtain measurements at any time, regardless of the season or cloud cover.

287 Passive systems are still more common than active systems.

288 Historically, the first images taken from airplanes date from the beginning of the 20th Century, followed 289 by the initial development of photogrammetry and applications of aerial photography in the 1920s. In the 1950s, as aerial photography became widely used, tree mapping was done by simple delineation or 292 and Leckie 1996). Soon after, spaceborne optical systems proved to be particularly useful for mapping 293 and monitoring forests at the national or even global level. Nowadays, the pace of technical 
advancement of sensors and platforms is more rapid than ever before. New developments in sensor 295 technology for airborne (digital aerial cameras, hyperspectral sensors, airborne laser scanning) and spaceborne (multispectral sensors, radar, airborne laser scanning) systems, such as greatly increased geometric, radiometric, and spectral resolution, lead to new perspectives for mapping woodland. In the last decade, great progress has been made in 3D remote sensing, including digital aerial stereo imagery, light detecting and ranging (LiDAR), and synthetic aperture radar (SAR) interferometry. The potential and use of currently implemented sensor systems for mapping woodland in general and individual tree species in particular, both passive and active, are described in more detail below. An overview of commercially available and frequently used sensors is given in Table 1. Principally, current digital data from any sensor system enables a high degree of automation in the forest mapping approach. The choice of the most adequate data set depends on several considerations such as temporal availability, costs, continuity, and the technical know-how of the operators. For large-area woodland mapping purposes, $30 \mathrm{~m}$ Landsat data might be a good alternative regarding costs and availability, since a huge worldwide archive exists. Archived images can be searched and obtained using the LandsatLook Viewer provided by the U.S. Geological Survey (USGS).

To guarantee a homogenous and integral woodland or forest cover map several factors need to be eliminated or at least minimized. First, the time span between the acquisition of data the mapping is based on and that for validation purposes should be minimized. This is an essential point because forest cover usually changes within a few years. Second, external factors (e.g., atmospheric influence, clouds, shadows, dust, and illumination factors such as sun angle and topography) should be reduced. While clouds and shadows might cover the area of interest, dust or illumination effects affect the reflectance of the forest canopy. Both result in a decrease in the accuracy of the mapped areas. Third, the optimal

\section{Passive systems}

Over the past decade, airborne photogrammetric film cameras used to extract individual tree crowns 324 radiometric resolution, and are regularly updated and available in almost all countries. Different studies 325 have successfully used digital aerial imagery to extract individual tree crowns (Hirschmugl et al. 2007, 
and Chubey et al. 2009), trees and shrubs (Waser et al. 2010), and to generate a countrywide wall-towall forest cover map (Waser et al. 2015). Other studies (e.g., Darvishsefat et al. 2002 and APEX 2011) underscore the advantages of using hyperspectral imagery with a spectrum range from $400-2,500 \mathrm{~nm}$ and between 100-300 image bands for tree species classifications and fewer for mapping forest. Over the past 30 years, spaceborne systems have also been successfully used for mapping woodland or forest, resulting in many mapping products (see Mapping Woodland and Forest on page xy). There is a broad range of spaceborne systems, including low spatial resolution (GSD 0.5-1 km) satellite systems such as NOAA AVHRR (e.g. Kennedy and Bertolo 2002) and SPOT4-VEGETATION (e.g. Stibig et al. 2004) for global applications, medium-resolution satellites (GSD 10-30 m) such as Landsat TM, ETM+ for national and continental applications (e.g. Keil et al. 1990; Pekkarinen et al. (2009), and ASTER (e.g. Stoffels et al. 2012).

Since the launch of IKONOS at the end of 1999, different series of very high resolution (VHR) satellite images exist (e.g., KOMPSAT-2, ORBVIEW-3, QUICKBIRD-2, RAPIDEYE, and WORLDVIEW-2) for mapping forest and forest type (e.g. Förster and Kleinschmit 2008, Immitzer et al. 2012, and Waser et al. 2014). With the exception of RAPIDEYE (only multispectral bands with GSD $6.5 \mathrm{~m}$ ), they provide all spatial resolutions for panchromatic images between 0.5 and $1 \mathrm{~m}$, and for multispectral images between $1.8 \mathrm{~m}$ and $6.5 \mathrm{~m}$. New perspectives for woodland and forest mapping regarding temporal and spatial resolution are provided by a group of upcoming new satellite sensors (e.g. WORLDVIEW-3 and Sentinel2 which carries an innovative wide swath high-resolution multispectral imager at 13 spectral bands). In addition to currently operational programs, there is continuous development of novel observation techniques, methodologies, and technology related to land use and land cover applications at a more scientific level.

\section{Active systems}

Approximately fifteen years ago, airborne laser scanning (ALS) generated considerable interest in the forestry sector. Providing 3D information to assess forest conditions has improved from the average forest stand scale to the individual tree scale. In the last decade, ALS has revolutionized the process of automated mapping of forest/non forest and has been frequently implemented (e.g., Næsset 2007; Straub et al. 2008; Eysn et al. 2015). Recently, full-waveform light detecting and ranging (LiDAR) systems have opened new perspectives by providing representations of both canopy profiles and surface topography. ALS campaigns have become more feasible at the countrywide scale, and new technologies have facilitated a more precise mapping of forest (Næsset and Gobakken 2005; Koch et al. 2009; 
Lindberg and Hollaus 2012; Straub et al. 2013). A good overview of individual tree cover and extraction using ALS data can be found in Kaartinen et al. (2012). Promising results for the extraction of woodland areas are obtained by combining LiDAR with multispectral images (Wang et al. 2007, Waser et al. 2015) or hyperspectral images (Dalponte et al. 2014).

Radar systems with synthetic aperture radar (SAR) sensors, such as ERS-1, ERS-2, ENVISAT and RADARSAT, have increased rapidly over the last few years, and have been used particularly in tropical regions for the detection of forest gaps or for delineation of forest boundaries (Fransson et al. 2007, Hajnsek et al. 2009). Since this method is unaffected by cloud cover and sun illumination, frequent updates of forest conditions of entire regions are possible (Rosenquist et al. 2007). SAR sensors have frequently been used to detect fragmentation (Dong et al. 2014), deforestation, and entire forest areas (e.g., Wagner et al. 2003, Thiel et al. 2006, Rahman and Sumantyo 2010).

\section{Processing of input data sets}

Prior to mapping woodland and forest, input data has to be prepared. The degree of automation possible and the number of steps required for this preparation will vary depending on the input data used and on the chosen mapping approach. The most common steps are briefly described below. From a methodological point of view, improved methods in image processing, automatic generation of DSM using new image matching methods, and image classification based on objects, have been developed in recent years. Meanwhile, computer systems and software packages are fast and typically easy to set up so that application can be made to large areas, for instance, when providing wall-to-wall products.

\section{Pre-processing of image data}

Data pre-processing incorporates atmospheric \& radiometric corrections of images, stereo-image matching, and the derivation of image features required for forest mapping. Atmospheric and radiometric corrections were originally developed for satellite images, and are frequently and necessarily applied to optimize image quality. The objective of atmospheric correction is to retrieve the surface reflectance (that characterizes surface properties) from image data by removing atmospheric effects that cause absorption and scattering of solar radiation. Radiometric correction is applied to remove radiometric errors or distortions (correction for sun angle and topography). Recently, new software packages also enable radiometric corrections for airborne sensors. For multi-scene applications and for image strips, it is strongly suggested to analyze radiometric corrections at least within-but preferably between as well-image strips from the same acquisition date. 


\section{Image based point clouds}

392 Image-based point clouds from stereo-images of airborne sensors are frequently used to calculate a 393 Digital Surface Model (DSM) in the context of forest mapping. In cases where both a digital surface 394 model (DSM) and a digital terrain model (DTM) (e.g. obtained from LiDAR) are available, the mapping 395 can be based on calculating a potential canopy cover by subtracting the DTM from the DSM (see Figures 3966 \& 7). While DSM and DTM on open ground can be derived from both ALS and from stereo-images, 397 DTM generation of forests is restricted to ALS. Point cloud data form images or ALS data have been used 398 operationally to map forest via automated delineation of forest/non forest vegetation (Straub et al. 399 2008; Koch et al. 2009; Waser et al. 2011, Waser et al. 2015). Enhanced image matching algorithms, 400 such as semi-global image matching (for example in Hirschmüller 2008) or similar multi-image matching 401 methods (Wagner 2011) permit the extraction of woodland with high accuracy and degree of detail 402 (e.g., forest borders and small openings between trees).

403 To separate non-vegetation objects (e.g. buildings) from high vegetation (tall shrubs or trees), 404 spectral information from aerial images (preferably from the near infrared band) or other types of 405 information extracted from them are used. For example, Ginzler and Hobi (2015) used the normalized 406 difference vegetation index (NDVI) to separate vegetation from non-vegetation areas and produced a 407 wall-to-wall vegetation height model (VHM) for Switzerland in its entirety. Since the near-infrared is 408 crucial for the detection of vegetation, separation problems arise if only true-color images are available. 409 In this case, a canopy height model (CHM) can be used - if stereo-images are available. If only a 3D point 410 cloud from an airborne laser scanning campaign is available, methods of echo-ratio are used to separate 411 vegetation from artificial objects (Eysn et al. 2012).

412 To summarize, image matching provides essential information-such as height information as shown 413 in Figure 7-about the surface of vegetation. Since it can be done using commercial software packages 414 and carried out semi-automatically, it requires relatively little expert knowledge. More expertise may be necessary to fully understand the algorithms employed. 


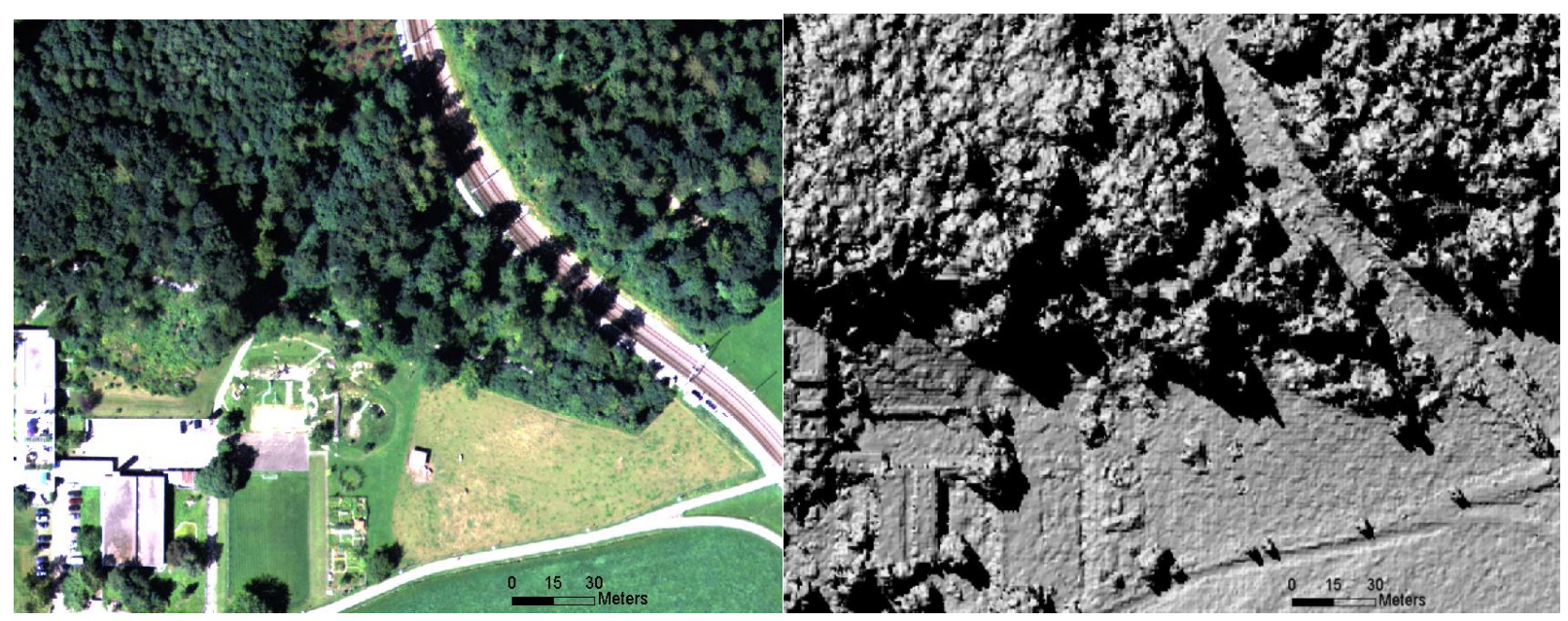

Figure 6. Example of airborne true-color orthoimage (left) with the corresponding hillshade of the potential canopy cover for a study area in Switzerland (right).

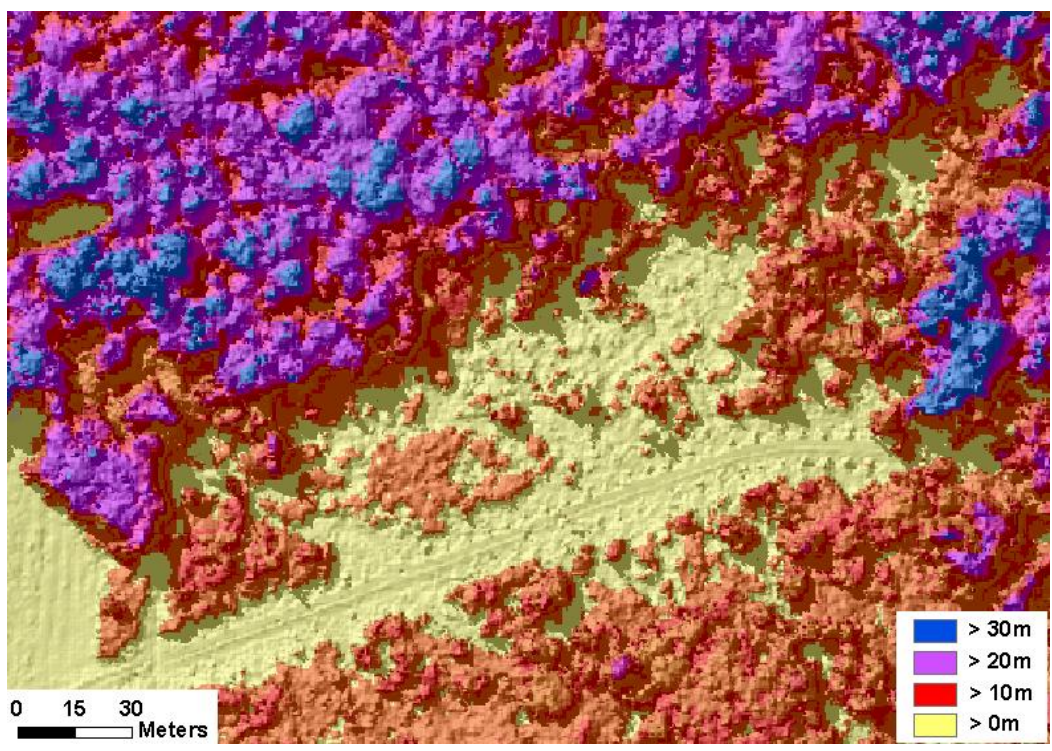

Figure 7. Hillshade of four different height classes obtained from a normalized DSM.

\section{Image segmentation}

The extraction of individual trees or groups of tree clusters is needed in the workflow of many highly automated mapping approaches and is often based on image segmentation. In this step, homogeneous image parts are subdivided into smaller patches or partitions. Nowadays, commercially available software packages are widely used making it possible to obtain optimal (according to the requirements of the mapping approach) image segments by iteratively adapting parameters such as the degree of homogeneity and the shape of image objects (Baatz and Schäpe 2000). Successful segmentation is 
430

431

432

433

434

435

436

437

438

439

440

441

followed by adjusting the size of objects to the scale of the assessment. For example, tree crowns and tree clusters must be adjusted differently when the mapping is set to the individual tree level or to the forest stand level. While image segmentation is carried out with a high degree of automation and is relatively simple using most software packages, problems occur when the area of interest increases. Depending on the level of detail and the spatial resolution of the images, these problems may already arise for areas of a few square kilometers. In such cases, subdividing the area into smaller parts can resolve the issue, but this will increase the required effort in terms of time and handling and consequently result in a loss of automation.

Thus, from a practical point of view, operational use on larger areas must be a compromise between the size of the area to be investigated and the level of detail. For example, it may be necessary to proceed at the stand-level scale rather than at the individual tree level. Figures 8 \& 9 illustrate aerial image segmentation at the individual tree level for mixed temperate stands.

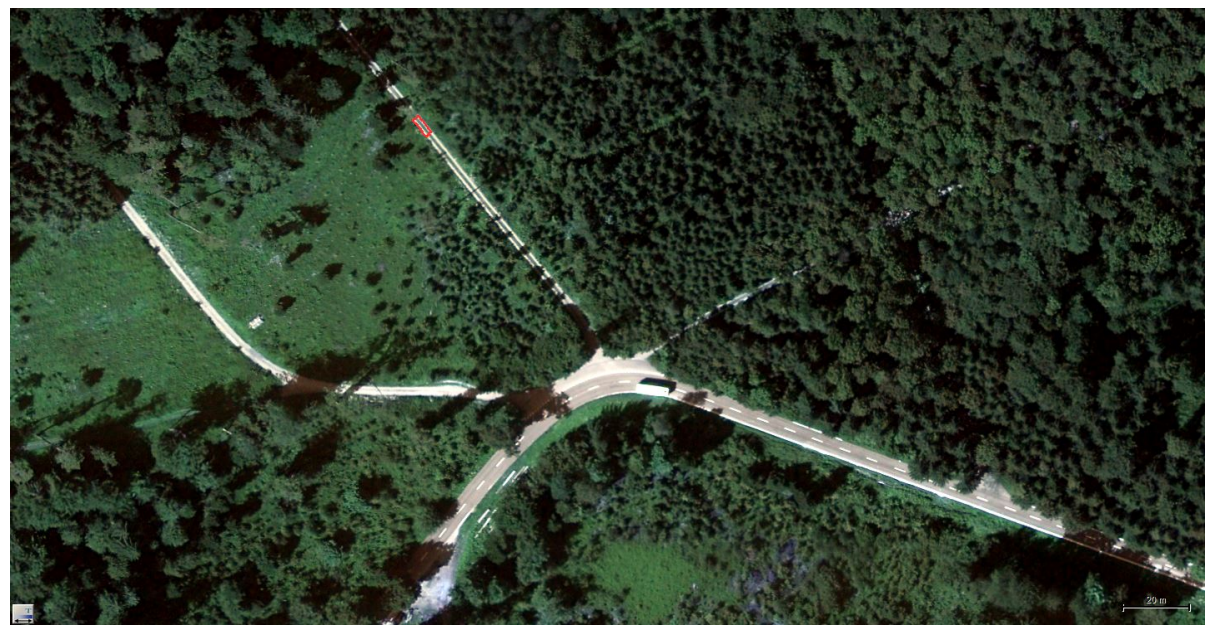

Figure 8. True color aerial image of different forest stands in a mixed temperate forest in Switzerland.

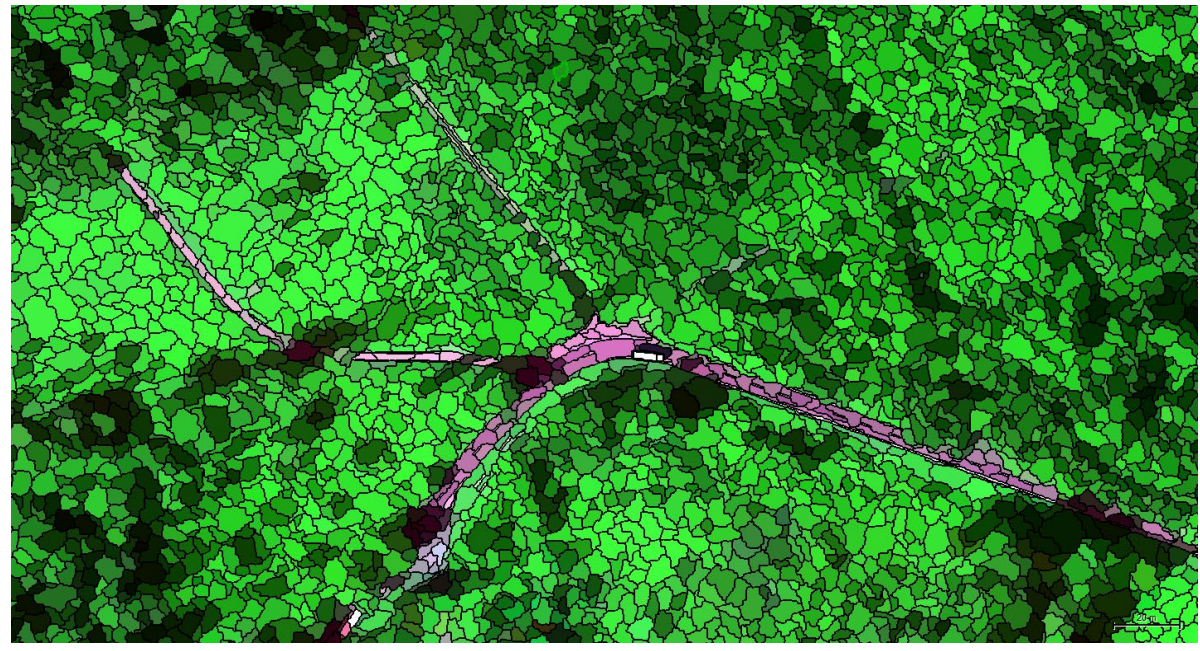


Figure 9. The same area with the corresponding image objects (different shades of green) after segmentation at the individual tree crown level.

\section{Image classification}

There are several other methods-with varying degrees of automation-of classifying images that are appropriate for mapping woodland areas and forest. Since image classification is crucial to the mapping process, important principles and background information are briefly outlined below.

Over the past decade, a number of significant developments in object-based image analysis-such as multi-resolution image segmentation and the identification of object relationships-have become available for classification purposes. According to Jensen (2005), the general objective of image classification is the automatic allocation of all pixels to land cover classes or specific themes. The most appropriate classification strategy depends on the biophysical characteristics of the research area. These include the topography or heterogeneity of the land cover, the homogeneity of the remote sensing data, the illumination level, the date of acquisition, the training data, the representative samples, and a priori knowledge.

Broadly, classification techniques can be categorized as follows:

- supervised: imposing our perceptions on the spectral data. Pixels or image objects are assigned to classes by matching them with spectral properties found in training data sets. Examples include minimum distance algorithms, maximum likelihood, more advanced techniques such as neural networks, fuzzy logic (see Chapter 6 - Fuzzy Classification of Vegetation for Ecosystem Mapping), support vector machine and regression techniques.

- unsupervised: spectral data imposes constraints on our interpretation and involves grouping data into categories based on some measure of inherent similarity. Separability of image clusters must be maximized. Class names are assigned to image clusters after classification (for example, k-means).

- parametric: based on probability density functions and the assumption that the data has come from a type of probability distribution (for example, discriminant analysis)

- non-parametric: based on probability density functions and no assumptions regarding the distribution of the data (for example, nearest neighbor)

Mapping woodland and forest is either carried out on entire forest patches or at the individual tree level (Leckie et al. 2003, Chubey et al. 2009). Several studies highlight the advantages of combining 
multi-resolution segmentation with object-based classification (Laliberte et al. 2004, Lamonaca et al.

477 2008, Waser et al. 2012).

478 In some studies, simple regression techniques were used to extract tree areas (Naesset and 479 Gobbaken 2005) or generalized linear models to assess tree and shrub probability (Waser et al. 2008a 480 and 2008b, 2011), since it is well known that a deterministic representation expressed in terms of a 481 limited number of land cover categories (e.g. trees, non-trees) leads to a loss of information. Still other 482 studies are based on local maxima algorithms (Koch et al. 2009, Dalponte et al. 2014, Eysn et al. 2015) or 483 in combination with a maximum likelihood classifier (Leckie et al. 2003). Examples of other techniques 484 include the use of fuzzy algorithms at the individual tree level (Brandtberg 2002), nearest neighbor 485 techniques (Laliberte et al. 2004), k-means clustering (Reitberger et al. 2006), and region merging 486 techniques (Wang et al. 2007).

487 An overview of studies that have successfully used remotely sensed data with the methods applied 488 for mapping woodland or forest is provided in Table 1.

Table 1. Overview of studies utilizing airborne and spaceborne remote sensing data for mapping forest and woodland. The table provides author references, location, data source, and method used.

\begin{tabular}{|c|c|c|c|}
\hline Study & Country & Data source & Method* \\
\hline Brandtberg (2002) & Sweden & Aerial images & FA \\
\hline Leckie et al. (2003) & Canada & Aerial images & $\mathrm{LM} / \mathrm{ML}$ \\
\hline Laliberte et al. (2004) & US-New Mexico & Aerial images & NN \\
\hline Leckie et al. (2005) & Canada & Aerial images & LM / ML \\
\hline Naesset and Gobbaken (2005) & Norway & LiDAR & REG \\
\hline Reitberger et al. (2006) & Germany & LiDAR & $\mathrm{KM}$ \\
\hline Straub et al. (2008) & Germany & LiDAR & REG \\
\hline Hirschmugl et al. (2007) & Austria & aerial images & RM \\
\hline Wang et al. (2007) & Switzerland & LiDAR, aerial images & RM \\
\hline Straub et al. (2008) & Germany & LiDAR & REG \\
\hline Waser et al. (2008 a\& b) & Switzerland & aerial images & REG \\
\hline Koch et al. (2009) & Germany & LiDAR & LM \\
\hline Waser et al. (2010) & Germany & aerial images & REG \\
\hline Waser et al. (2011) & Switzerland & aerial images & REG \\
\hline
\end{tabular}




\begin{tabular}{llll} 
Eysn et al. (2012) & Austria & LiDAR & LM \\
Kaartinen et al. (2012) & Finland & LiDAR & LM, RM, KM \\
Waser (2012) & Switzerland & aerial images & REG \\
Dalponte et al. (2014) & Norway & LiDAR, aerial images & LM \\
Eysn et al. (2015) & Central Europe & LIDAR & LM \\
Waser et al. (2015) & Switzerland & Aerial images & TH \\
\hline Dees et al. (1998) & Germany & Landsat & REG \\
Kennedy and Bertolo (2002) & Europe & AVHRR & REG \\
Stibig et al. (2004) & SE Asia & SPOT-4 & KM \\
Laliberte et al. (2004) & US-New Mexico & Quickbird & NN \\
Förster et al. (2005) & Germany & ASTER, SPOT-5 & FA \\
Förster and Kleinschmit (2008) & Germany & Quickbird-2 & FA \\
Pekkarinen et al. (2009) & Europe & Landsat ETM & NN \\
Hansen et al. (2013) & Global & Landsat TM, ETM & REG \\
\hline \hline
\end{tabular}

*Methods: Fuzzy algorithms (FA), k-means clustering (KM), k-nearest neighbor (kNN), Linear discriminant analysis

492 (LDA), Local minima / maxima (LM), Maximum likelihood (ML), Nearest neighbor (NN), Regression techniques

493 (REG), Region growing or merging (RM), Quadratic discriminant analysis (QDA), unsupervised (US), thresholds (TH).

\section{Mapping woodland}

This section illustrates three highly automated approaches to mapping woodland in different biogeographical regions in Switzerland. For each approach, the basics of each method, data, results (tables, but especially figures and illustrations), and a discussion of pros and cons are given.

\section{A hierarchical segmentation approach for mapping woodland}

The principles of image segmentation are given in the section Image segmentation. Mean-shift-a non-parametric statistical method-is a special form of segmentation which was originally presented by 504 Fukunaga and Hostetler (1975) and generalized by Cheng (1995) 20 years later. It is a robust and highly 505 automated algorithm, and is based on a simple iterative procedure that shifts each data point in the feature space (n-dimensions where the imagery variables or canopy height are) to the average of data points in its neighborhood. The algorithm is frequently applied to color images because most of the generated regions can be delineated semantically. The algorithm starts by converting the image data 
into a feature space. For each data point, the mean-shift algorithm defines a window around it and

510 computes the mean of the data point. The algorithm associates each data point with the nearby peak as

511 identified by the dataset's probability function. The center of the window then shifts to the mean. The

512 algorithm is repeated until it converges. Finally, each pixel is grouped together based on all

513 corresponding convergence points. Figure 10 shows an example of the resulting segmentation of one

514 false color-infrared (CIR) aerial image with the segmented region borders indicated with yellow lines.

515
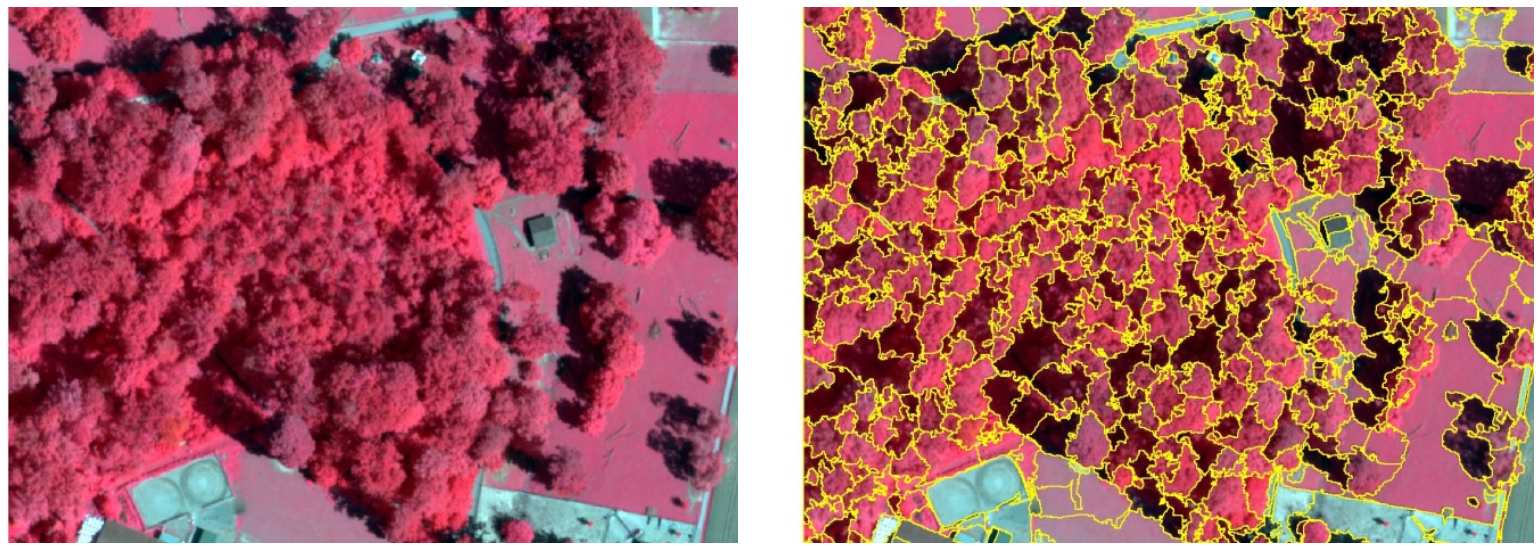

Figure 10. False color infrared aerial image of woodland (left) and the segmented crowns obtained by mean-shift segmentation (right).

516

This relatively simple technique for most pixel-based tree canopy mapping creates thresholds for either single bands of the image or derived data such as NDVI. Similarly, there are two important thresholds, one of which is the NDVI value and the other is the CHM value. In general, the rule is set whereby a segment is identified as woodland if the mean values of NDVI and CHM of all pixels within one segment are higher than the predefined thresholds. Segments containing shadows, for example, along the boundaries of a woodland, may also include groups of trees. Since these segments can be extracted as woodland, a slight overestimation of woodland is thus obtained. Consequently, a hierarchical segmentation approach is implemented because of the advantages of color-infrared and NDVI images. Figure 11 shows a hierarchical segmentation method flow chart. The two thresholds $\psi$ are applied to NDVI and $\lambda$ to CHM data. The segment is classified as wooded-area if its mean values of NDVI and $\mathrm{CHM}$ are higher than the pre-defined thresholds. Woodland is then classified using the segments as obtained in woody1 and woody2.

The results produced provide the basis for various forest applications, including the calculation of canopy cover, forest area delineation using explicit definitions and the extraction of gaps in forest 
531 masks. Due to the highly automated processing chain, further extended study areas would need to be 532 investigated in order to verify the different threshold combinations.

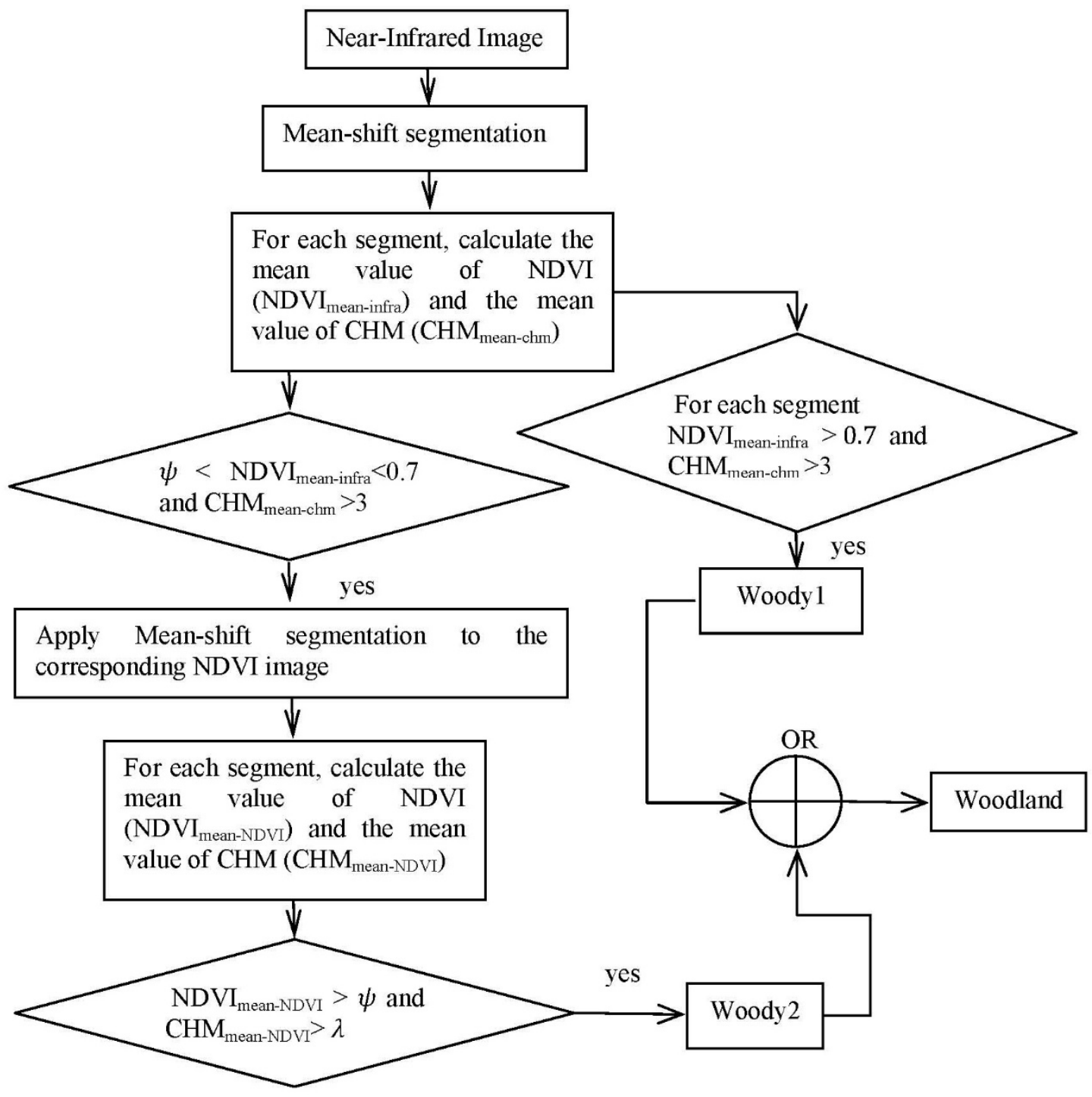



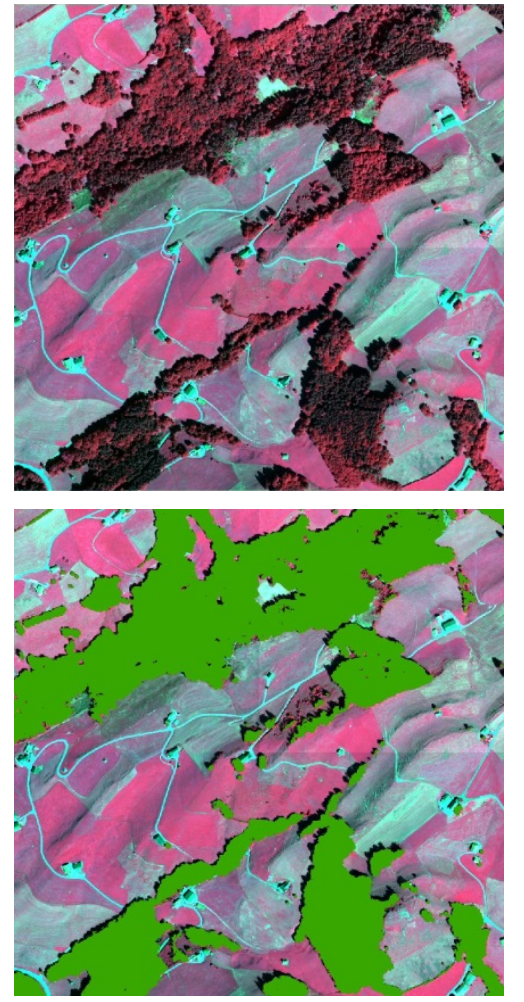

Close forest
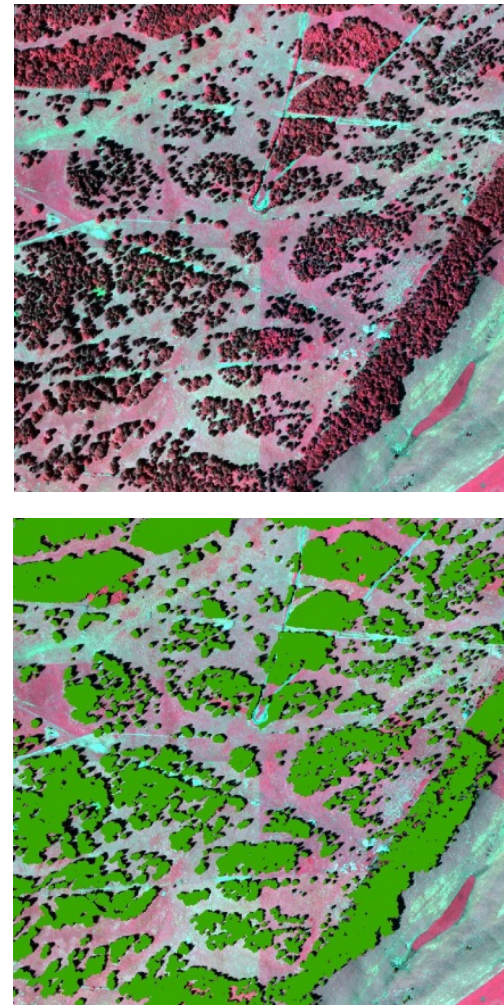

Open forest
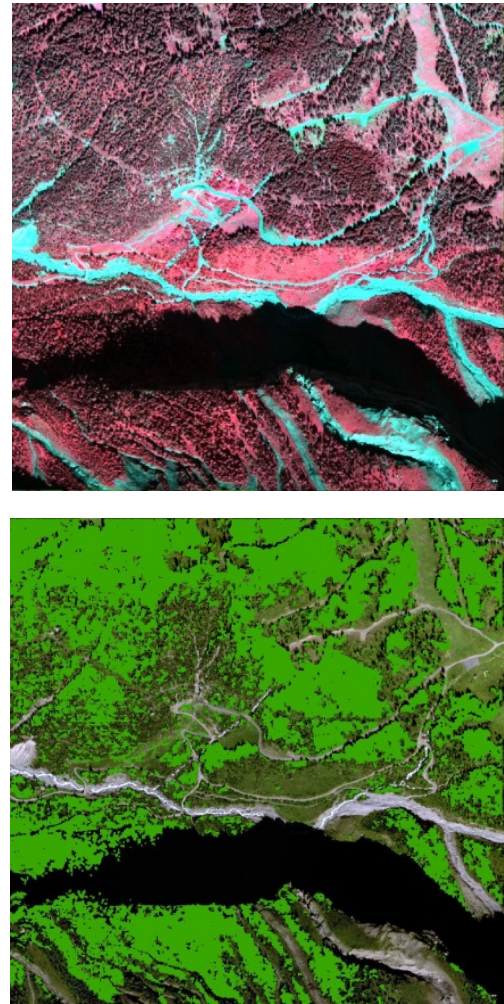

Mixed forests
541

542

543

544

545

546

547

548

549

550

551

552

553

554

555

Figure 12. Examples of CIR images with different woodland and different types of mapped forests.

\section{Individual tree and tree crown detection}

Tree height and crown geometry are two basic woodland features from a remote sensing perspective and complement spectral information with rigid geometry. Numerous highly automated approaches based on ALS or image matching have been proposed to detect individual trees (ITD) and individual tree crowns (ITC). Most of these focus on the reconstruction of the DSM or CHM, which provides a representation of the outer geometry of tree canopies. DSMs from ALS data or from image matching are the starting point for the detection of individual tree crowns and the calculation of tree parameters, such as height and crown diameter. Depending on the available point density of the DSM, the location of individual trees, the shape of tree crowns or the canopy cover, can be estimated with decreasing point density. The average point density mainly controls the selection of an appropriate smooth or coarse shape model. Robust ITD using ALS data requires a point density of 2 points $/ \mathrm{m}^{2}$ or higher. Most 
approaches start by finding a local height maxima in the DSM. For subsequent processing of local neighborhood region-growings (Solberg et al. 2006), height histogram (Kartinen and Hyyppä, 2008), watershed (Straub and Heipke 2001) or cluster analysis (Kartinen et al. 2012) methods are used.

In the case of coarser CHMs, tree crown or canopy shape models can be applied, of which the most common shape approximations use an ellipsoid of rotation (Welles and Norman 1991; Nilson and Peterson 1991; Li and Strahler 1992; Li et al. 1995; Kuusk and Nilson 2000; Garcia-Haro and Sommer 2002; Gerard and North 1997; Gerard 2003). Slightly refined models use a combination of a cone on top of a cylinder (Nilson and Peterson 1991; Chen and Leblanc 1997; Kuusk and Nilson 2000), implement a fixed shape model with adaptive diameter (Vosselman 2003) or use a predefined set of fixed shape models (Rutzinger et al. 2010). For low point densities-which are often the case with large DSMs-less sophisticated shape models are required. A very common terrain shape indicator is curvature (2nd derivative, and has been used in many applications for terrain analysis - Zeverbergen and Thorne 1987). The most prominent disadvantages of the curvature feature are the limited neighborhood ( $3 \times 3$ box), the requirement of an interpolated grid, and the fact that it has no fitting with a shape model. Curvature processing often results in a highly overestimated number of tree crowns and is consequently only of limited use.

For example, in Switzerland, $40 \%$ of the coverage area of the Swiss National DSM has a point density of less than 1 point per square meter. As a result, robust detection of ITCs is not possible with the shape models discussed above. Consequently, another model is required, which combines local maxima value with a shape fitting approach. The so-called spider-model (Figure 13) implements a non-parametric shape description with few global spatial constraints, mainly to avoid finding a suitable parameter set for the processing of a national dataset. In the first step, a local maxima must exist within a $3 \times 3$ neighborhood. In the second step, for each of the 8 directions from the center, the slope values are accumulated for each direction independently. Each slope accumulator contains (n-1)/2 values, i.e. 4 slope values for each leg of a 9x9 box. Each slope value in the accumulator must be within the limits of 5 - 85 degrees to be considered valid. In this way, horizontal and vertical slope extremes are rejected. If all slope values are valid, the corresponding direction is classified as a canopy leg candidate (invalid legs are dashed in Figure 13). If 6 out of 8 canopy legs are valid and radially contiguous, then the area of the 8 slope accumulators will be defined as a canopy patch. The robustness of shape matching is achieved with the non-parametric evaluation of the slope accumulator and the concept of allowed limited local distortions (invalid legs). Using a moving window, the processing of the DSM results in a point cloud of 


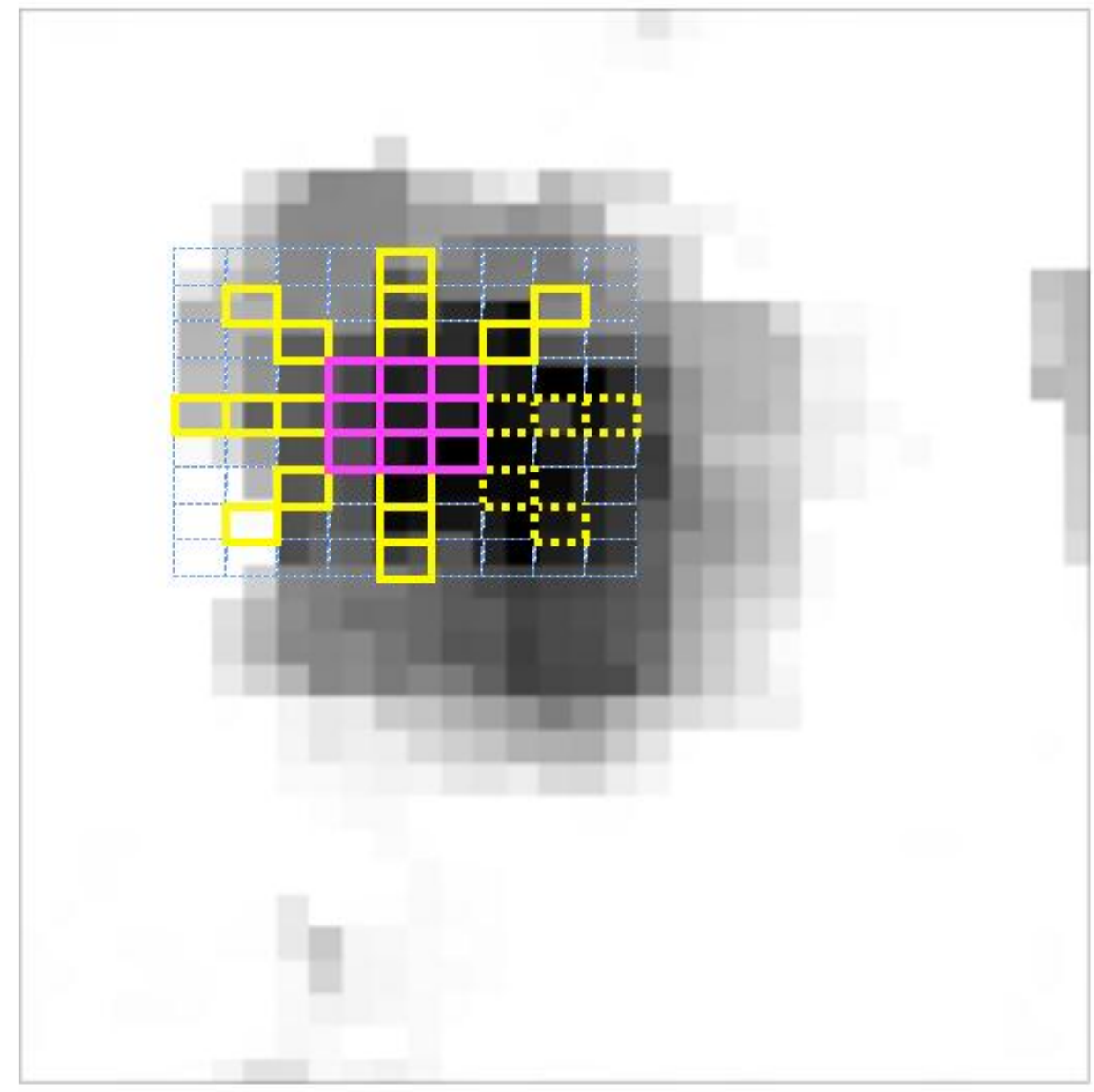

Figure 13: The Spider-model which combines local maxima and a minimal shape fitting of an individual tree crown.

592 The height classes of an individual tree are indicated in grey to black. The six canopy legs are yellow, of which the two dashed legs are invalid (the cells of these legs are not within the 5 - 85 degree limits).

The presented shape model requires only a few parameters compared to other shape models, which 596 is a clear advantage with regards to the degree of automation, robustness, and parameter evaluation. 597 With the increasing spatial resolution power of future aerial cameras, the spider-shaped model is still 598 appropriate to extract single tree crowns from low quality digital surface models. On the other hand, the 599 lack of a rigid shape model can be seen as a conceptual disadvantage, which occasionally results in the 600 matching of distorted tree canopies. This compromise, however, achieves the desired degree of 601 robustness. 


\section{Fractional tree cover approach}

604 The fractional tree cover approach has been applied to several forest ecosystems in central Europe 605 and involves the continuous representation of probabilities ( $P$ woodland) that each image segment is a 606 tree/shrub or not. The fractional tree cover approach is based on logistic regression models and is 607 described in detail in Waser et al. 2008a and 2010. The logistic regression model is a special case of the 608 generalized linear model (GLM). The linear result is run through a logistic function, which runs from 0 609 (negative infinity) and rises monotonically to 1 (positive infinity). Tree probability ( $P$ woodland) ranges 610 between 0 and 1 for each pixel that belongs to the class woodland (for more details, see Hosmer and 611 Lemeshow 2000). Thus, woodland is continuously mapped in detail and is, therefore, particularly useful 612 for detecting single trees, small trees, and shrubs. Waser (2012) reported that a high degree of 613 automation was achieved with the developed methods, and that trees and shrubs were extracted with a 614 correct classification rate (CCR) of 96-99\%. Visual image inspection revealed that the fractional cover 615 approach was also accurate in areas with complex forest structures, such as open forest and gaps, 616 afforestation, and fuzzy borders - especially in steep terrain. The fractional tree cover approach consists 617 of four main steps. Figure $\mathbf{1 4}$ gives an overview of the methodological workflow. 


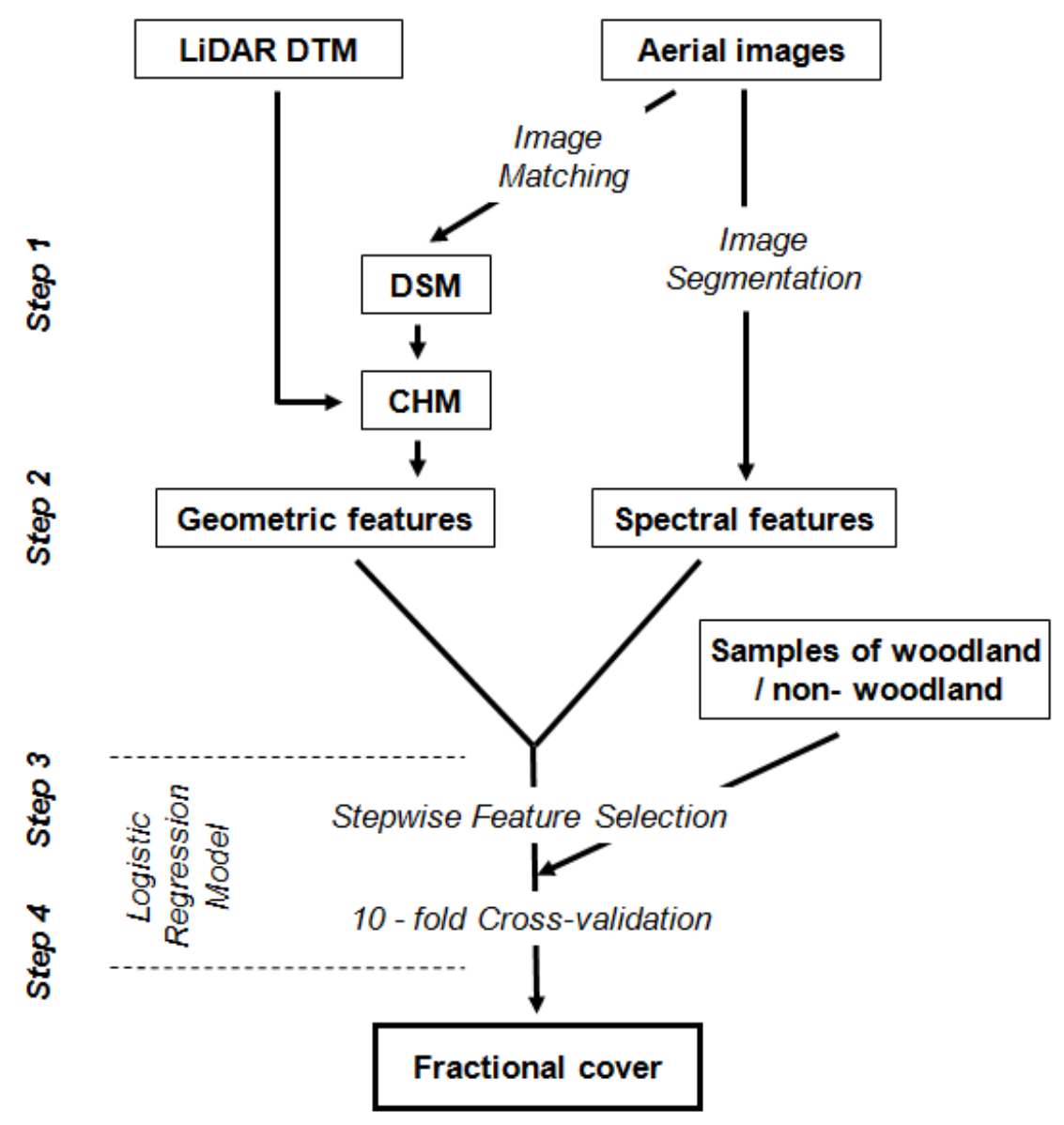

Figure 14. Methodological workflow of extracting woodland using logistic regression models.

620 First, potential tree crowns are segmented (as described in Image Segmentation on page xy) and a high621 resolution CHM is generated by subtracting the DTM (derived from LiDAR) from the DSM (derived from 622 image matching). Second, geometric features (height, slope) are generated from the CHM, and spectral 623 features from digital aerial images (original image bands, color transformation, and NDVI). Digitized 624 polygons of woodland/non-woodland samples (as described above in the section Reference Data) are 625 used as training and validation data. Third, step-wise feature selection is used as an analytical tool to 626 find redundant features which are then excluded from the model. Fourth, the predictive power of the 627 models is then verified by a 10 -fold cross-validation process using different combinations of selected 628 features.

629 Usually, good mapping results are obtained if all tree segments with $P$ woodland probabilities of 630 greater than 0.5 are included. In the case of overestimated woodland-for example because of 631 grassland on boulders which may be wrongly mapped as trees because of their similarity to real trees 632 and shrubs - the $P$ woodland threshold can be adapted accordingly by lowering it, for example, to 0.3 . 
633 This must be done after the first run and is strongly dependent on the individual terrain and vegetation 634 characteristics of the area to be investigated. Thus, the fractional tree cover approach enables the 635 averaging out of possible over- and underestimations, and has high potential to successfully extract 636 shrubs and small single trees. The limitations of this approach include constraints regarding full 637 automation, and the potential lack of sufficient reference data, in particular when mapping large areas 638 with time restrictions or when reference data simply does not exist. Applying the latest image matching 639 algorithms may improve accuracy at forest borders and small openings between them by improving the 640 generation of the geometric features. An example is provided from a mountainous test site in central 641 Switzerland (Figure 15: photo of the test site; Figure 16: true color orthoimage; Figure 17: estimated 642 woodland probabilities).

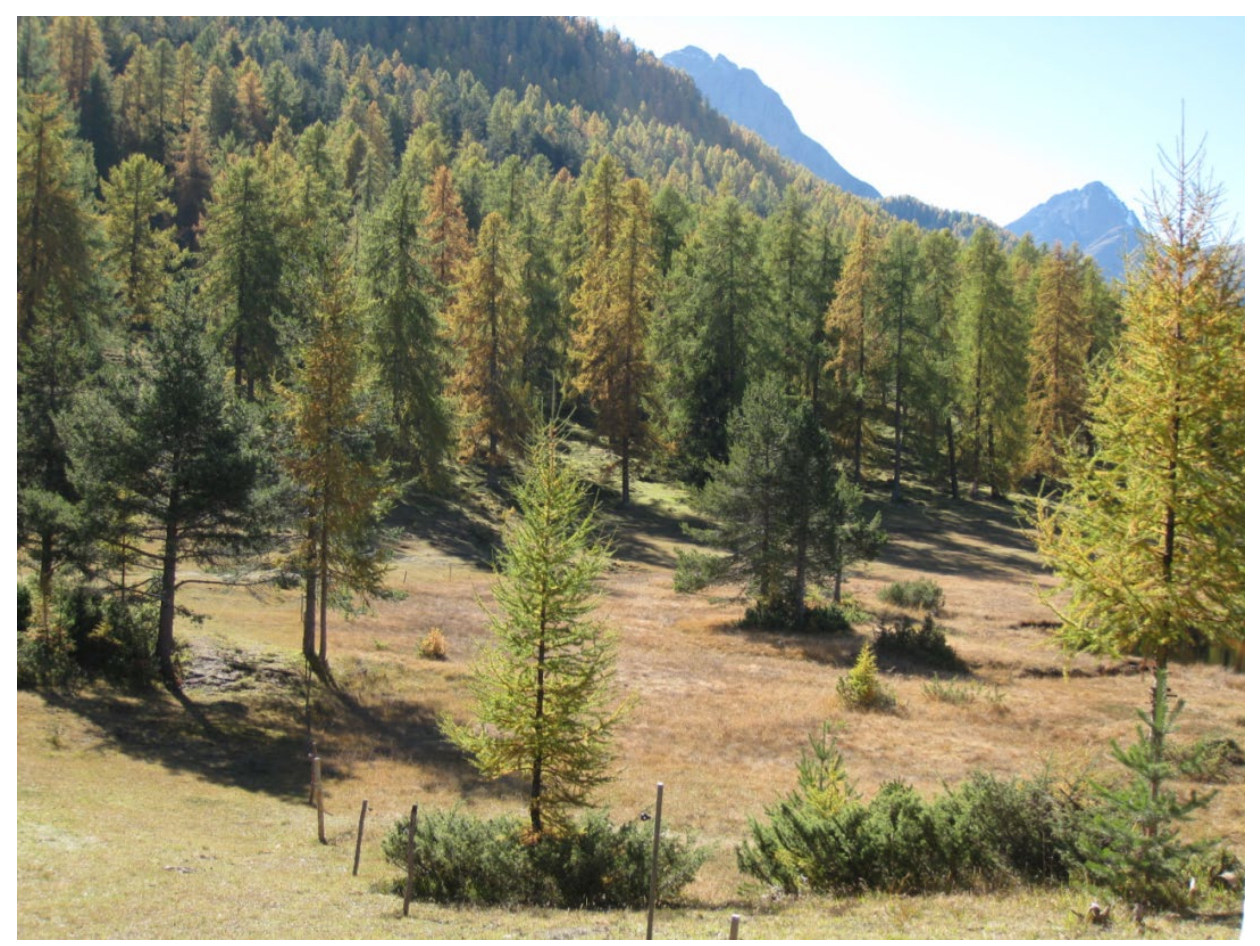

644 Figure 15. Example of mountain woodland where the fractional cover is tested from the center of Figure 16 to the 645 south west. Larch, spruce, and shrubs dominate the area. 


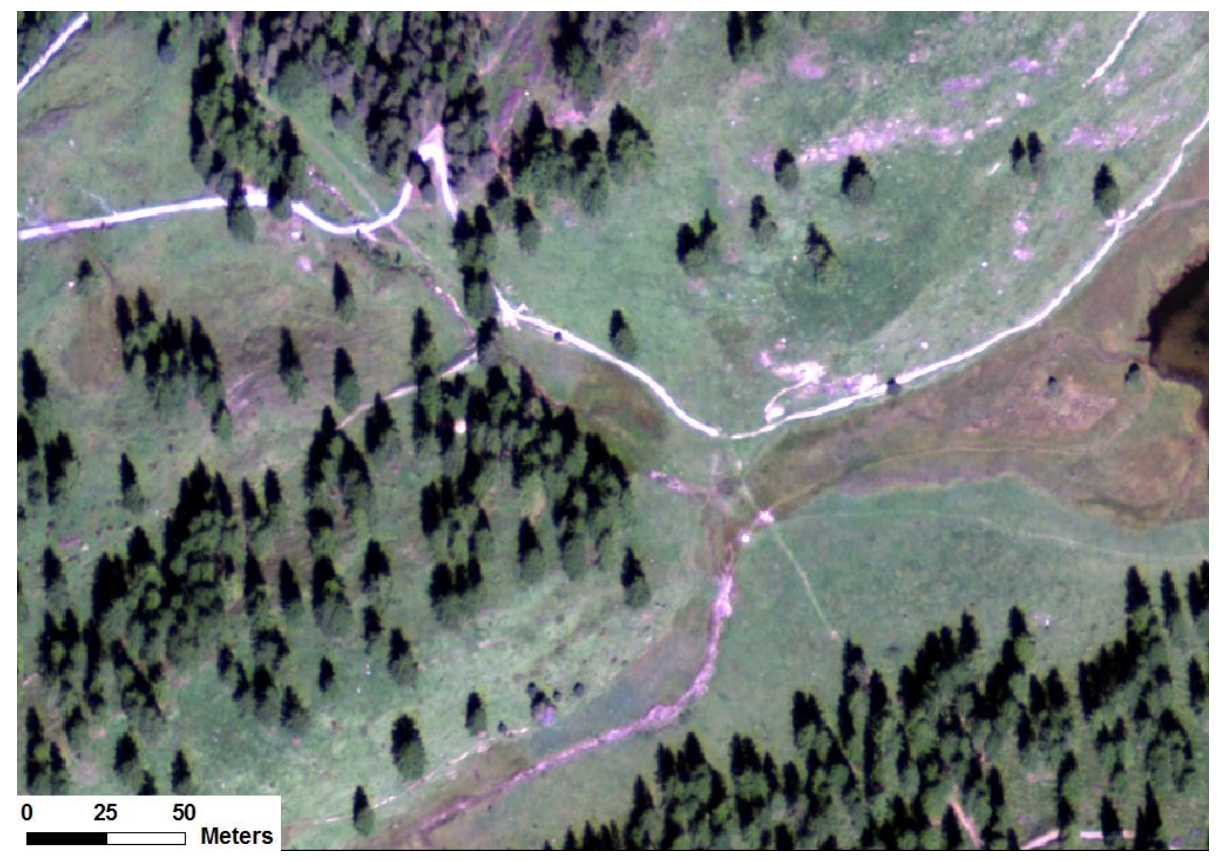

Figure 16. A true color aerial image of woodland in the central Alps of Switzerland.

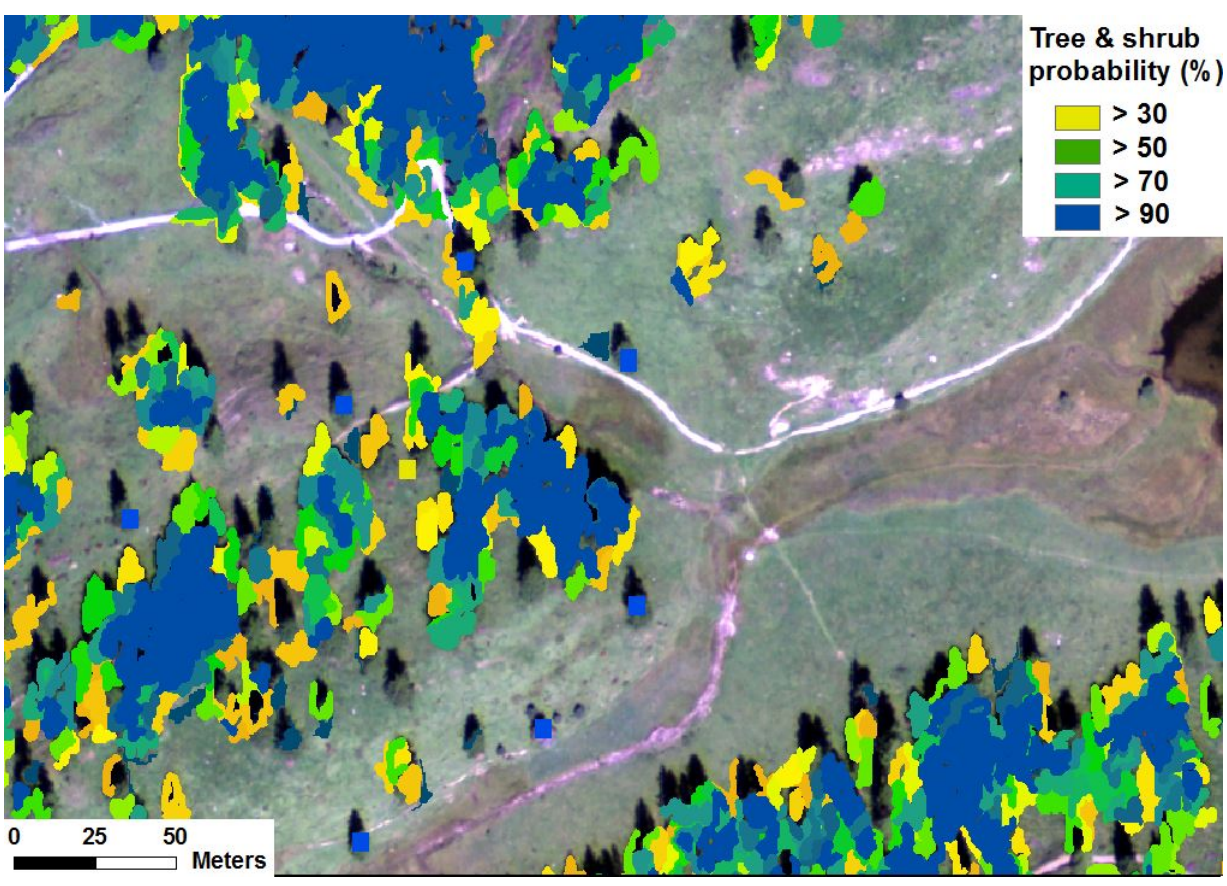

Figure 17. Mapped woodland (trees and large shrubs) for the same area. The higher the probability for trees and shrubs, the darker the color. Small trees are extracted as well.

\section{Forest mapping}

As stressed several times in this chapter, in contrast to mapping woodland, forest mapping implies an unambiguous definition for forest. Two highly automated approaches are presented here for forest 
mapping which are based on merging the wooded areas with forest areas using distance and height criteria. Thus, they can be easily adapted to any forest definition. Each approach includes a short description of method, data, results (tables, but especially figures and illustrations), the use of different definitions for forest, and a discussion of pros (potential) and cons. The impact of minimum areas, minimum width, crown coverage, the importance of land use definitions, and their impact on forest areas are also discussed. The results derived from these applications are highly dependent on the fundamental input parameters' size, and position of the delineated forest areas.

\section{Moving window approach}

A highly automated workflow based on ArcGIS functions implemented in Python scripts was developed to generate a wall-to-wall forest cover map of Switzerland. The approach is based on the four key criteria (1) minimum tree height; (2) minimum tree crown coverage; (3) minimum width; and (4) land use. The description of this approach below was originally published in Waser et al. (2015) and is only partly modified.

Whereas fairly straightforward and automated methods to obtain criteria 1-3 from remote sensing data exist, the land use criterion is not easily assessable when using remotely sensed data. Due the limitations explained in the Introduction, the land use criterion cannot be directly obtained from remotely sensed data. Instead, existing map products must be taken into account, which may have a different scale or level of detail compared to the remote sensing data used for forest mapping. The forest mapping approach is suitable for very high resolution data from airborne laser scanning (ALS) or digital stereo aerial images. The moving window approach is highly automated and uses threshold techniques in combination with the three criteria above and a land use definition. Thus, its suitability for NFI purposes is entirely supported by the application of the land use criterion and its high level of detail, especially regarding forest borders and gaps.

An overview of the main steps and input data sets are shown in Figure 18. The four key criteria of the NFI forest definition are explained separately and in more detail below. Figure 18A shows a vegetation height model (VHM) based on image-based point clouds with a spatial resolution of $1 \mathrm{~m}$ - which was derived from aerial image blocks of $0.5 \mathrm{~km} \times 0.5 \mathrm{~km}$ (Ginzler and Hobi 2015). Figure 18B shows a preliminary forest cover map based on the criteria of the NFI forest definition (minimum tree height, crown coverage, and minimum width). Figure $18 \mathrm{C}$ shows the application of the land use criterion in order to remove forest on other land (e.g., orchards, urban parks) while adding temporarily unstocked 
forests (e.g., wind throw, harvesting). Finally, in Figure 18D, the calculated forest cover map that implements all criteria of the forest definition as used in the stereo-image interpretation of the Swiss $\mathrm{NFI}$ is shown.

691

(A)

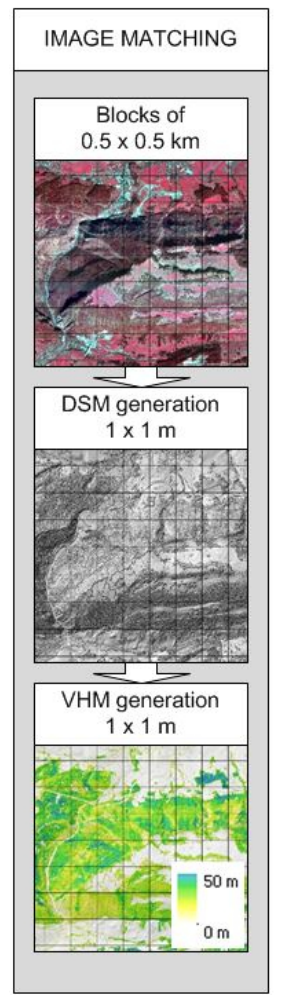

(B)

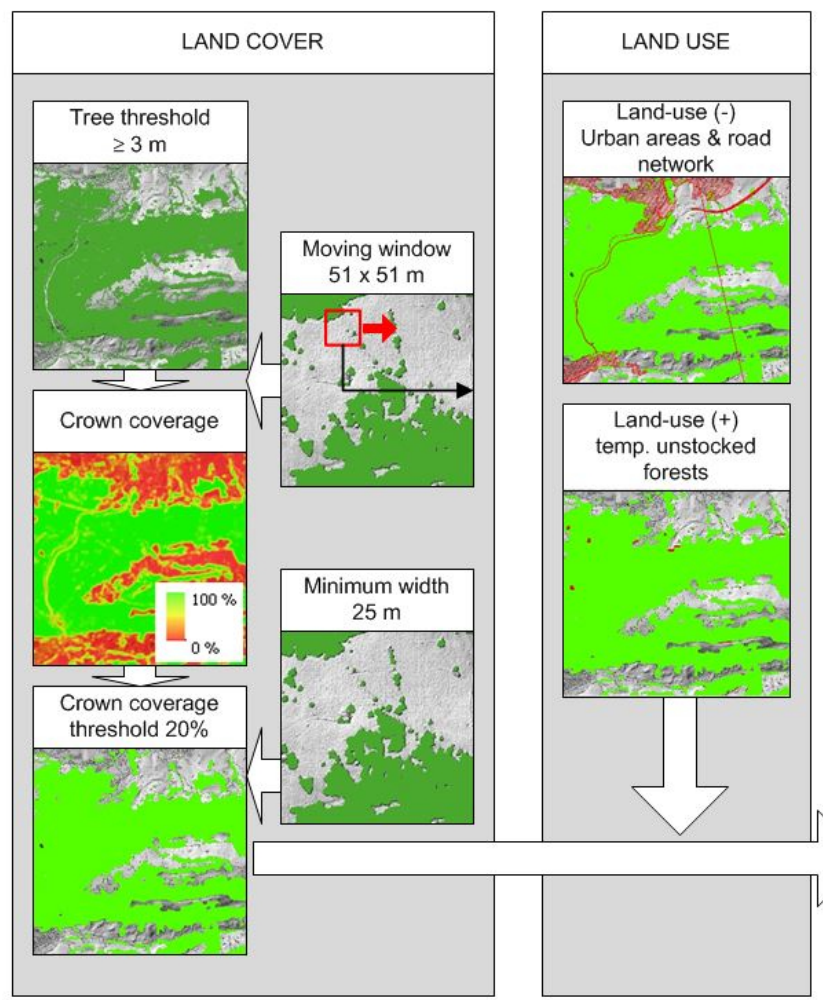

(D)

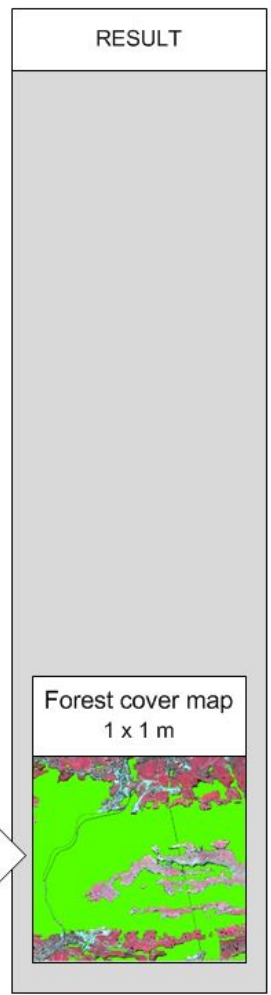

Figure18. Workflow of the forest cover map implementing the existing Swiss NFI forest definition. (A) image matching, (B) preliminary forest cover map based on land cover and the thresholds and criteria of the NFI forest definition (minimum tree height, crown coverage, and width), (C) removal of forest on other land and addition of temporarily unstocked forests, (D) final forest cover map (source: Waser et al. 2015).

\section{Height}

Terrestrial height measurements are often time consuming for several reasons. In dense forests, it is more challenging to see tree tops from the ground than in open forests. Furthermore, broadleaf trees are even more difficult and ambiguous to measure than coniferous trees, because of the round shape of the crown. Height information-measured remotely using active systems such as ALS or passive systems such as stereo images - can be applied to large areas with high densities. Given a precise DTM from an ALS campaign, the height of objects can be calculated by subtracting the DTM from the elevation above 
sea level of the surface model. The result is a CHM with a level of detail which depends on the resolution

706 (point density) of the input DTM and DSM.

707 To separate trees from other woodland, a height threshold, as specified by a particular forest definition, 708 is used. In the Swiss National Forest Inventory, the minimum tree height is set to three meters (see 709 Figure 19). In contrast, in most NFIs and the FAO, the definition of forest specifies a higher minimum 710 tree height of five meters. Regardless of the NFI, height is always clearly defined as "height in situ", 711 which in fact refers to the height a tree may reach under site-specific conditions in the field and not the 712 actual height. In this way, temporarily un-stocked areas (e.g. harvested areas) retain the classification of 713 forest in the framework of a forest inventory, but are not detected as forests when using a CHM.

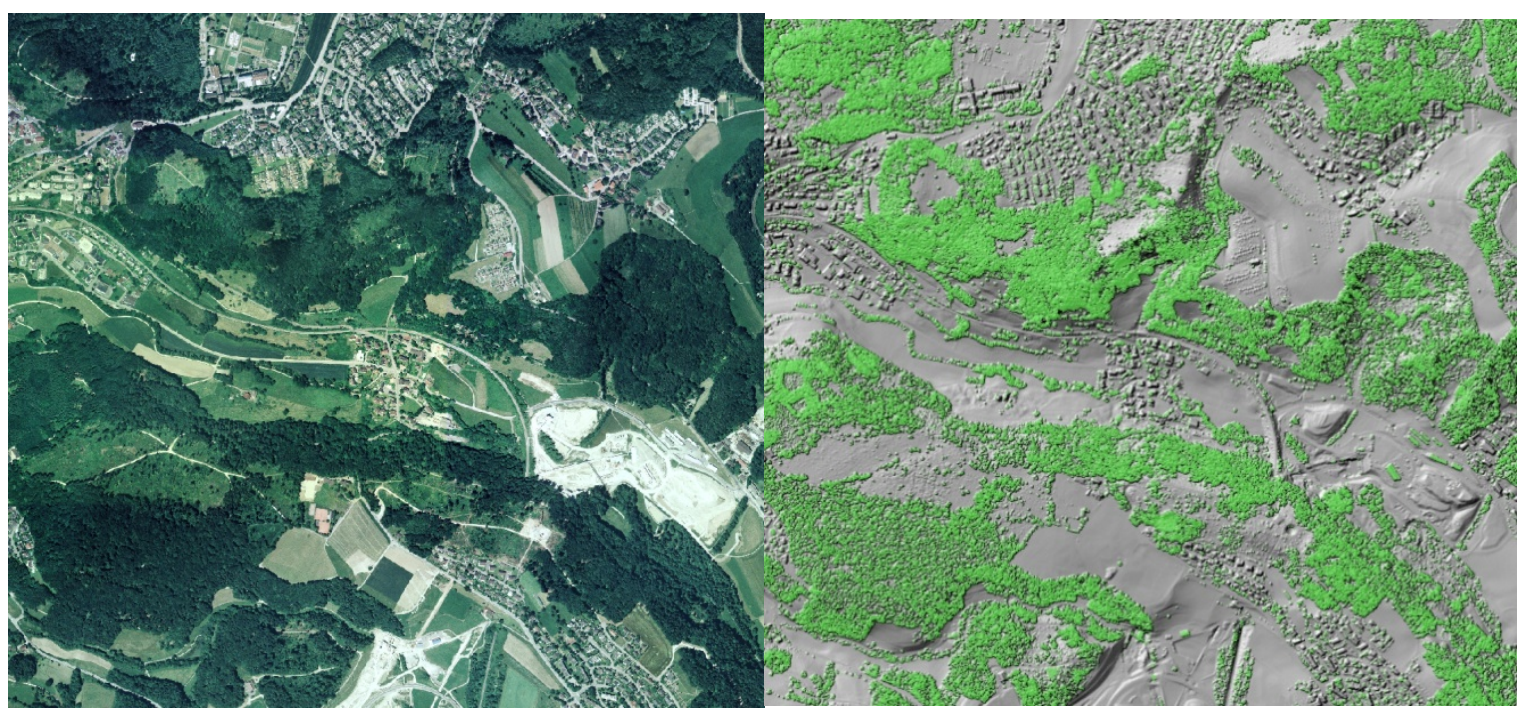

715 716 717

718

719

720

721

722

723

724

725

726

Figure 19. Stocked areas in the true color aerial image (left). CHM with extracted trees based on the 3-m height criterion as applied in the Swiss NFI (right).

\section{Crown coverage}

For the calculation of crown coverage, a well-defined reference area is essential, which is usually an interpretation area of a fixed size, as used by forest inventories (an area of $50 \mathrm{~m} \times 50 \mathrm{~m}$ is used by the Swiss NFI). Alternatively, forest stand maps can be used to estimate canopy cover. Crown coverage is calculated using a moving window approach, with a rectangle of $51 \mathrm{~m} \times 51 \mathrm{~m}$ (odd number in order to obtain the center pixel) which almost corresponds to the interpretation area used in the Swiss NFI terrestrial survey and in the stereo-image interpretation. For each center pixel, the proportion of vegetation greater than or equal to $3 \mathrm{~m}$ in height inside the window is calculated and the defined minimum crown coverage of $20 \%$ (Swiss NFI definition) is applied. Other definitions of forest are in the 

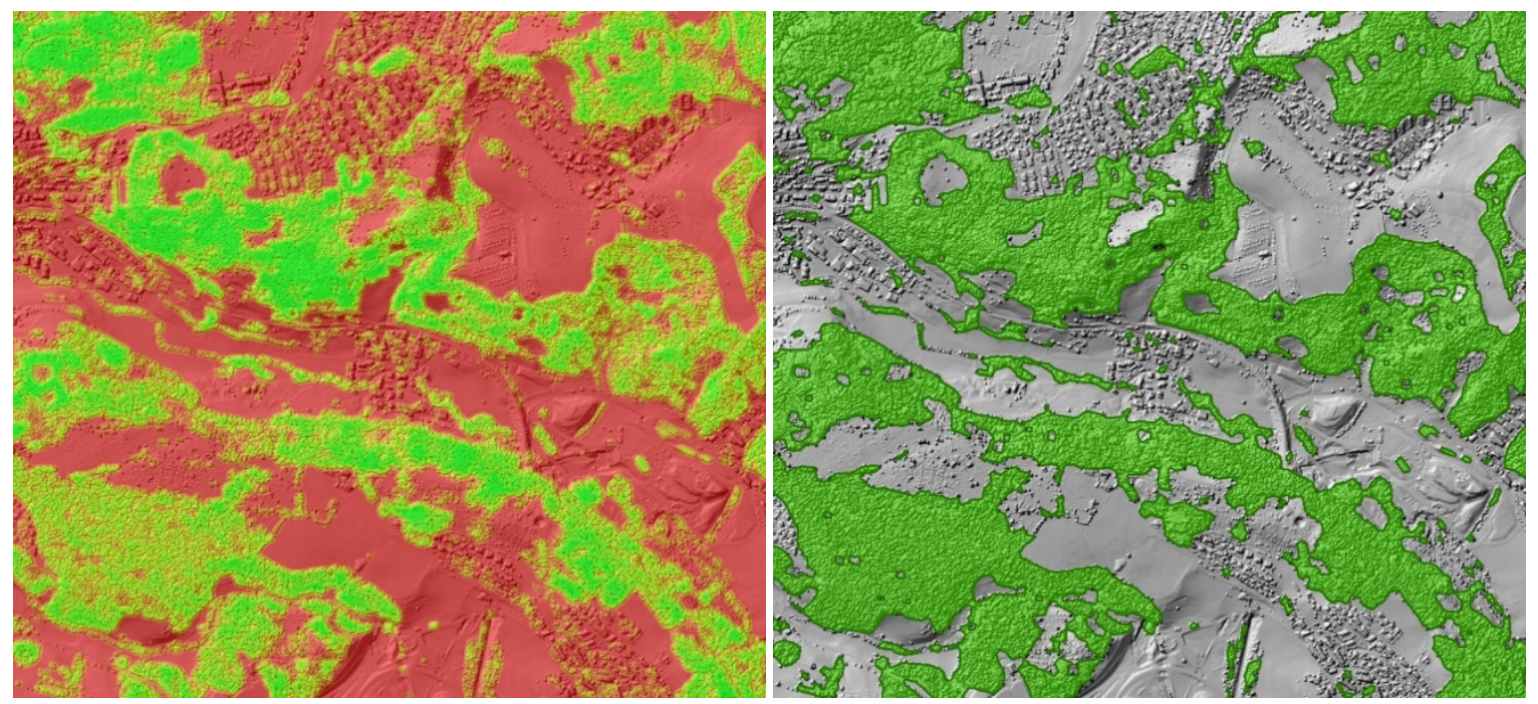

Figure 20. Extracted tree coverage (crown coverage of 0\%-red, 100\%-green) based on the moving window approach as applied in Switzerland (left). Example of the same subset after applying a minimal crown coverage threshold of $20 \%$ (right).
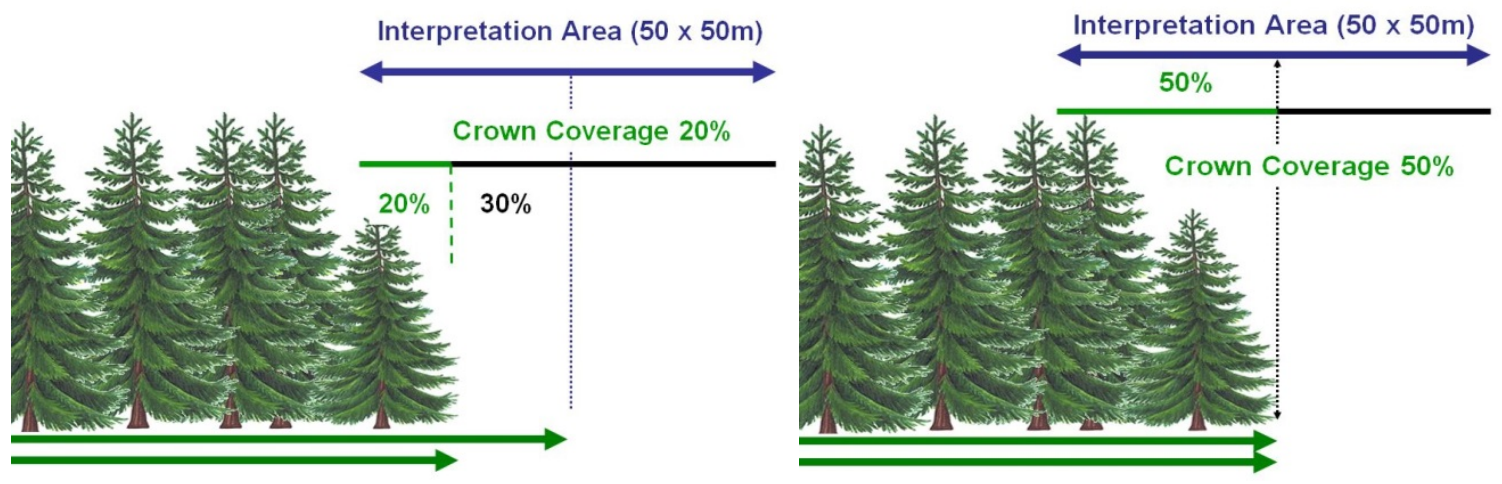

Figure 21. Problems related to the forest area at forest borders within the interpretation area (blue line) 
Figure 21 (left) illustrates that crown coverage is still 20\% at the position of the dashed line, even though the center of the interpretation area is clearly outside the desired forested area as defined by the NFI. After the preliminary forest cover map was generated using the $20 \%$ crown coverage threshold, the map was shrunk using morphological functions. The number of pixels for the shrinkage process at a specific position $i(\mathrm{XY}$-coordinates of this pixel) is a function of the size of the interpretation area and the minimum crown coverage threshold as described in equation 1.

Number of pixels to shrink $k_{i}=$ window size $\times(0.5$ - crown coverage threshold $) \times$ crown coverage ${ }_{i}$

Applying the Swiss NFI forest definition this value is $51 \mathrm{~m}$ (window size) $\times(0.5-0.2)$ (20\% crown coverage threshold $) \times 1(100 \%$ crown coverage at this location inside the forest $)=15.3$ pixels (rounded to 15). For the sake of simplification, the crown coverage inside the forest border at any location can be set to $100 \%$, resulting in equation 2 .

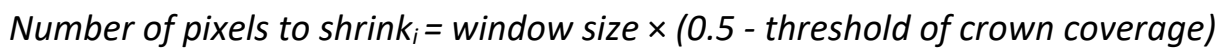

Figure 21 (right) illustrates the example for a 50\% crown coverage threshold within the interpretation area. In this case, no shrinkage would be applied.

\section{Minimum area and width}

Minimum area and width are two other essential parameters needed for forest mapping. However, both are handled differently by many NFIs. Minimum width is more frequently used to separate areas of narrow tree elements-which do not fulfil the minimum requirements of the forest definition-from clearly defined forest areas. While minimum area is relatively simple to calculate using standard GIS functions, more effort is needed for minimum width. A frequently used method is to place a circle, with the radius of the minimum width inside the stocked area. In this ideal case, the minimum width criteria is fulfilled. If not, another possibility is to calculate these distances with triangulation by setting the length of the minimum triangle to the required width threshold. In the given example (Figure 22 on the left), narrow tree groups below the minimum width of $25 \mathrm{~m}$ were removed using morphological functions while preserving the shape and size of larger objects. The forest cover map was first shrunk by half of the minimum width of the forest definition and then expanded by half of the minimum width. Parts smaller than the minimum width criterion were assigned the value zero (non-forest) and thus remain non-forest after the expansion of the shrunk forest cover map. 

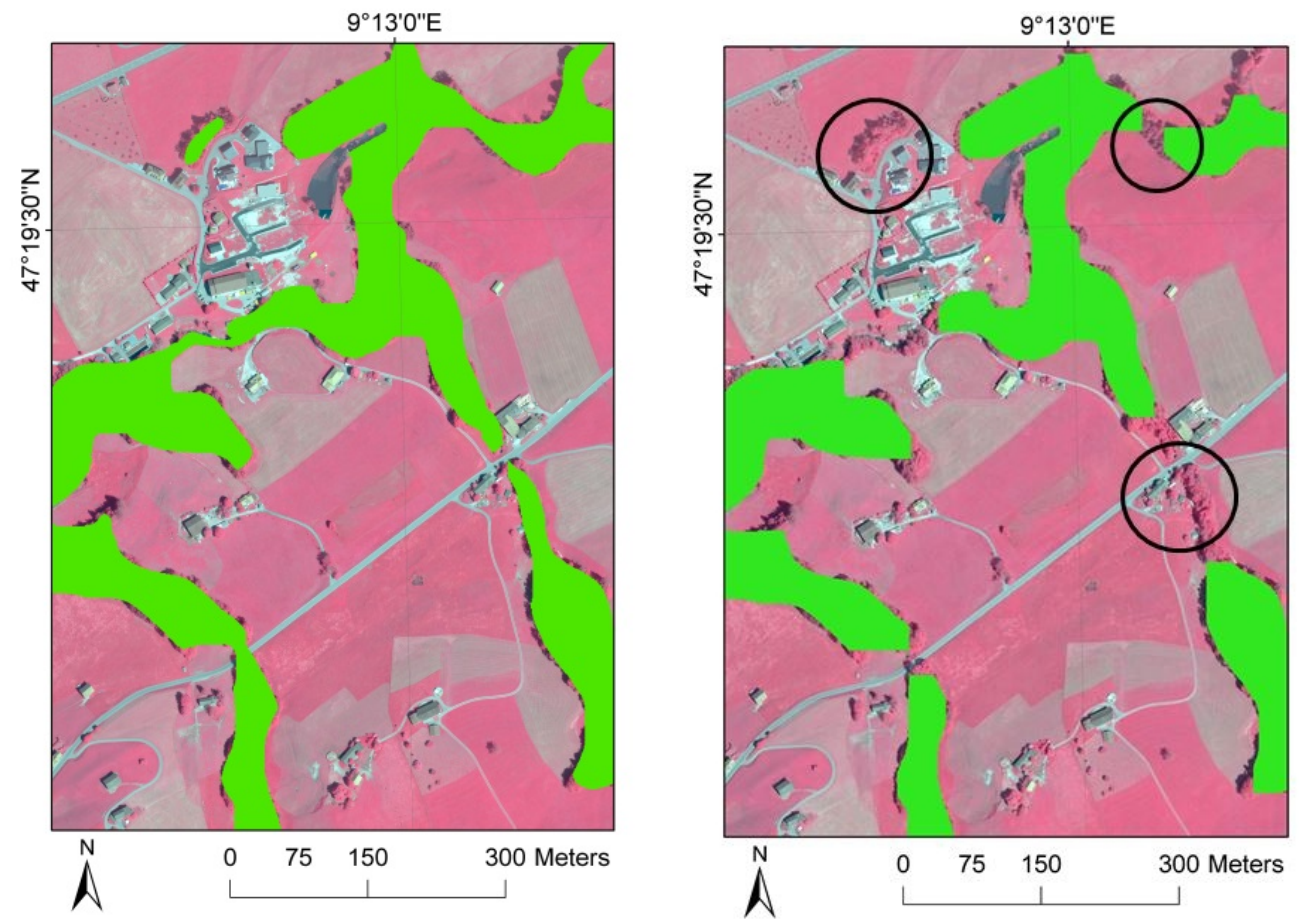

775

776

777

778

779

780

781

782

783

784

785

786

787

788

789

790

791

Figure 22 Removal of narrow tree elements from the forest cover map using morphological filters. Forest cover map after applying the crown coverage threshold of $20 \%$ (left). Removed narrow elements (circles) in the expanded forest cover map with half of the minimum width threshold (right) (Source: Waser et al., 2015).

\section{Land use}

Since the land use criterion could not be obtained from the VHM or from aerial images, it was implemented using the respective cover from the Topographic Landscape Model (TLM) (for more details see Swisstopo 2016). It is superior to the currently available CORINE 2006 land cover (CLC2006) with respect to the level of detail and updating, and is the best available proxy for the forestry land use. Two classes from the TLM were integrated into the present forest mapping approach: the land cover class closed forest-which is actually a land use class-to compensate for temporarily unstocked forests, and the land use class orchards and settlement to eliminate forest area on other land uses. In contrast to the three other criteria, additional manual work was necessary since the exact forest definition applied in the TLM is not entirely clear. Both TLM land layers were visually checked and polygons that were obviously wrong or too generalized were manually deleted. 
Distance criterion approach

793 Another often used approach for forest mapping is based on the distance criterion. The approach is 794 highly automated and aggregates point clouds from both image matching or ALS to forest layers within a 795 spatial grouping process as described below. Similar to the moving window approach, the three criteria 796 of height, minimum width, and minimum crown coverage are used from the forest definition. Thus, in 797 the first step, the height criterion of greater than $3 \mathrm{~m}$ based on the VHM according to the Swiss NFI 798 forest definition is applied to the woodland. Figure $\mathbf{2 2}$ gives an overview of the distance criterion 799 approach.

800

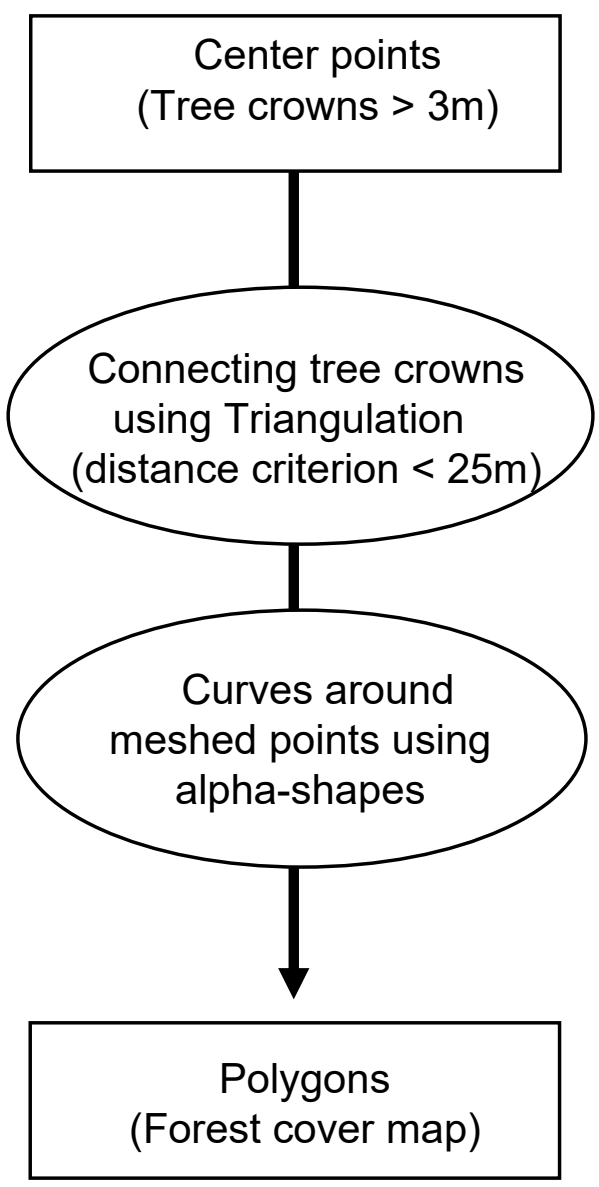

801

Figure 22. Overview of the methodological workflow of the distance criterion approach based on Delaunay triangulation and alpha-shapes. 
In the first step, the two criteria of minimum crown coverage and minimum width/area from the NFI

806 forest definition are obtained indirectly using the distance criterion as described below. The previously extracted centers of individual tree crowns $(>3 \mathrm{~m}$ ) are connected in a non-overlapping mesh using Delaunay triangulation based on a distance criterion (e.g., minimum width of $25 \mathrm{~m}$ as defined by the Swiss NFI). In the second step, the shape of the point sample on its surface is reconstructed using alpha

810 shapes. The alpha shapes define a piecewise linear curve around the meshed points. The resulting alpha hull (Figure 23 on the right) surrounds the tree crown centers and avoids the overestimation of forest

812 area resulting from the overinclusion of empty areas (Mottus et al. 2006; Vauhkonen et al. 2012;

813 Edelsbrunner 1995).

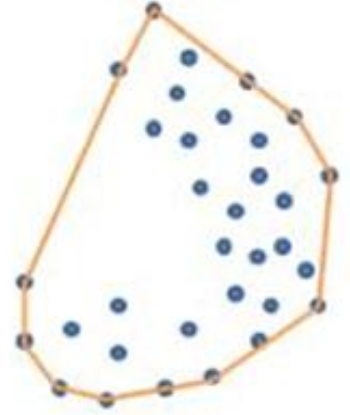

Convex hull

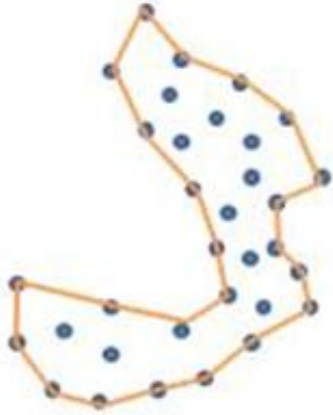

Concave hull
815

816

817

818

819

Figure 23. The principle of convex and alpha hulls (red line) of points belonging to tree crown centers. Based on the distance criterion, a tree crown lies within a certain distance from its neighbors.

The triangulation of point clouds and the calculation of the alpha hull is closely related to the problem of correct connectivity within a given point cloud (Figure 24).

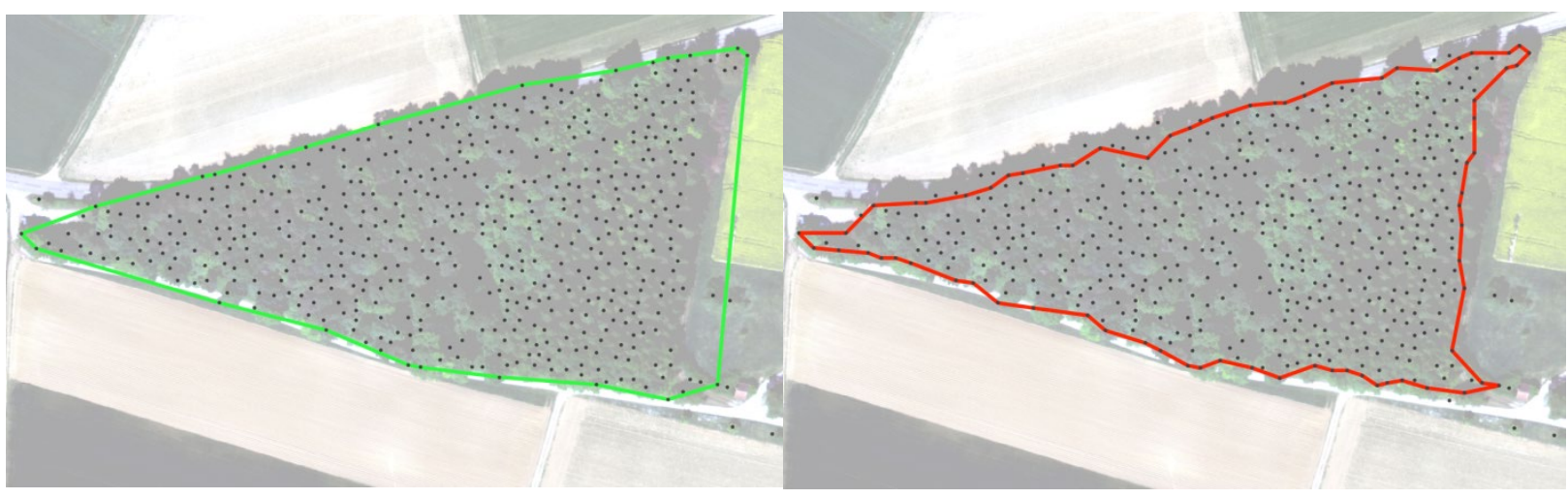


823 The definition of an appropriate connectivity distance is a crucial point. For the Swiss NFI, this distance 824 corresponds to a minimum width of $25 \mathrm{~m}$. The required control of connectivity can be achieved by a 825 preliminary triangulation with a strict distance constraint. Thus, points within a certain distance metric $826(<25 \mathrm{~m})$ belong to the same object, and only for these points will the alpha hull be calculated (regions $\mathrm{A}$, 827 B and $C$ in Figure 25). The maximum distance is required for all three vertices within each triangle. 828 Therefore, linearly aligned points (narrow tree areas such as tree rows, single trees) do not meet the 829 requirements for a spatial object (region E in Figure 25). If the distance is too great from surrounding 830 points, topological holes will be created (region D in Figure 25). Thus, forest gaps and clearings are well 831 extracted.

832

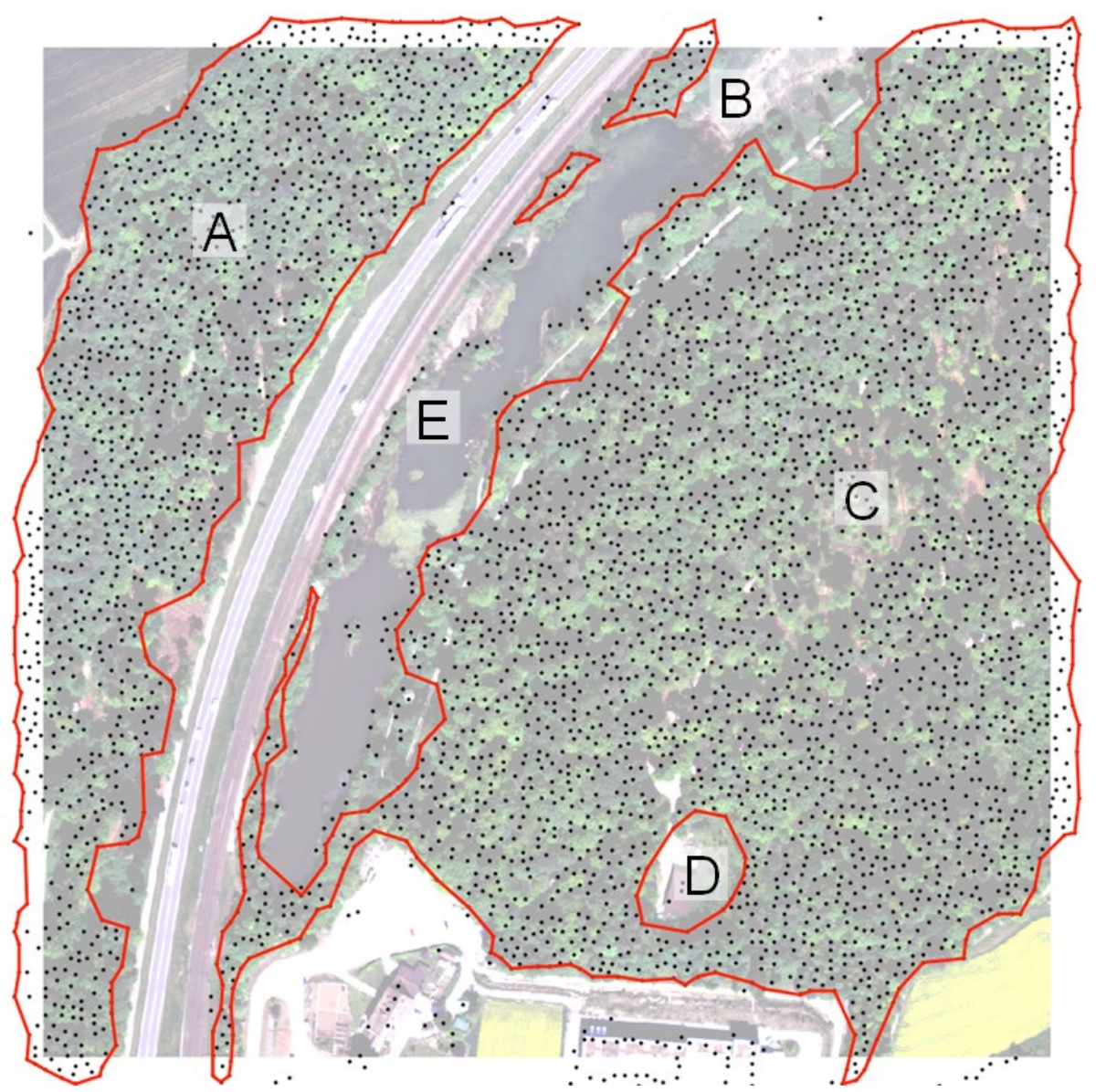

Figure 25. Triangulation with the distance-constraint and alpha hulls (red lines) of tree crown centers (dots) with a true color orthoimage as background. Calculated alpha hulls for points within dense forests (A), forest aisles (B), and open forest (C). The building is extracted as a topological hole (D). Tree rows are not extracted due to their 
Grouping methods for forest data are strongly related to the application-defined requirements for connectivity and generalization. This approach makes it possible to control the distance- and shaperelated grouping process with only two parameters, and can therefore be easily adapted for a wide range of forest applications. Triangulation enables a more appropriate handling of the spatial

842 distribution of point data compared to cluster approaches. For some applications, it could be necessary

843 to use weighted point data, mainly when specific features of forest data are much more important than spatial distributions (e.g., diameter, health status).

\section{Lessons learned}

Nowadays, most existing forest cover maps are still the product of visual interpretation of aerial or satellite images with automation mostly restricted to the processing the input data. While only a few of these automated methods are currently operationalized and applied to large areas, most have been tested within the framework of case studies.

In this chapter, the potential of remote sensing data and techniques towards automated woodland and, in particular, forest mapping has been illustrated. The presented approaches are promising and, because of their automation potential, superior to existing approaches. Because they make use of airborne or spaceborne sensors, and optical data sets can be applied entailing lower costs and less complex data processing and handling, they can be regarded as state-of-the art, and may be used to gather accurate up-to-date information on forest areas at different scales, including small wooded patterns and single trees. The most likely interest groups that could benefit from the presented mapping approaches are public or private authorities with environmental or forest-related concerns, private environmental agencies, forest districts, private forest owners, and NFIs.

The approaches illustrated here are straightforward from a methodological point of view (well862 level and not only at the case study level. They are also highly automated and applicable to larger areas. 863 However, each of the illustrated approaches still consist of steps that need some manual adaptation of 864 parameters. This applies both regarding the processing of data sets, such as the segmentation of images, 865 and the checking of existing training data, or, if not available, the generation of such training data (e.g., 866 digitizing polygon samples).

867 Automation is reduced when mapping forest is entirely based on a NFI definition, less because of the 868 calculation of geometric parameters (minimum height, minimum crown coverage, and minimum 
width/area), but more because of the implementation of a land use criterion. The latter may require the appropriate collection of relevant land use information.

From a technical point of view, current handling of large data sets is no longer a problem. In theory, processing and data storage can be done using standard personal computers. However, for wall-to-wall forest cover maps, multi-core computers with large physical memories are recommended. This is not only in order to minimize processing time but also to optimize and speed up each step of the applied mapping approach because most software packages enable the use of clusters for faster calculations.

There are, however, several significant constraints that remain. First, the implicit term forest is not always correctly used by the remote sensing community and is confused with woodland, since it only comprises a minimum height criterion. Thus, prior to the use of any mapping approach, unambiguous definitions of forest and non-forest are indispensable. Regardless of the applications, the FAO definitions seem to be reliable. Problems regarding automation increase for cross-border mapping approaches because harmonization of existing forest definitions are additionally necessary. Manual interactions and processing steps are also required, such as merging different remote sensing data sets, and harmonizing different forest definition criteria (minimum height, crown coverage and width/area).

A second area of concern is the implementation of a land use criterion, which, in turn, has an impact on the definition of forest. Although remote sensing methods enable woodland mapping, the limitations of forest mapping increase if land use is incorporated. Although land cover can be easily and directly assessed using remote sensing data and techniques, for land use it is less straightforward, requiring a combination of image classification expertise and external knowledge. Interviewing foresters or performing in situ field visits of the areas under examination are recommended. Problems also arise if remote sensing-based mapping products are combined with statistically estimated NFI products. In addition to the decreased processing automation, comparisons of the extracted mapped forest areas must be handled with care.

A third concern is that forest mapping may also be challenging because of the huge variety of existing remote sensing data and methods. However, the value of the final map product strongly depends on the requirements of the end user. Thus, in order to maximize automation, a precise understanding of these requirements-that incorporates the end user's needs, budget, availability of training, and the validation, quality, and handling of the remote sensing data must be worked out. In addition, weather conditions (clouds) may also affect the planning process, and a certain degree of flexibility may be needed if alternative data material must be used. Furthermore, the time span between data sets should be kept to a minimum. 
A fourth issue is that automation strongly depends on the collection of training data which902 although a labor intensive part of the mapping process-will substantially reduce future work by the implementation of existing NFI sample plot data, such as tree/non-tree information (based on stereoimage interpretation), and terrestrial information (obtained from field visits) within the framework of a $\mathrm{NFI}$.

\section{Future perspectives}

Technical developments in remote sensing data and collection methods in the near future, and the increasing need and demand for long-term forest cover maps, will further push and improve the automation of such products.

Current trends in spaceborne remote sensing also appear promising in a number of ways for the land use and land cover assessment community. The provision of larger swath-widths in combination with more bands and high temporal resolution (on the order of a few days) will significantly enhance the operational forest monitoring capabilities of entire countries. Sustainability of such applications is

915 currently supported by the Landsat data continuity mission and systems that are being promoted by the European Space Agency (ESA) and the European Commission (EC) Global Monitoring for Environment and Security (GMES) program. The ESA's Sentinels program-which provides dedicated spaceborne satellite missions that address the operational user and institutional needs within the wider European Copernicus (former GMES) initiative-represents a major step forward. Dedicated to Copernicus, Sentinel-1 already ensures the continuity of C-band SAR data collection (planned launch of Sentinel-2 in April 2016, building on ESA's and Canada's heritage SAR systems on ERS-1, ERS-2, ENVISAT and RADARSAT). Full-waveform LiDAR data (as presented in Mapping Forest 3D Heterogeneity Using Waveform Lidar) also has great potential. These programs provide high quality 3D information as required by many processing steps in the derivation of $\mathrm{CHM}$ or geometric features for forest definitions. Moreover, they are the current standard in many countries and acquired in cycles of 3-6 years.

A higher degree of automation can be achieved by simplifying the methodological workflow using modern machine learning algorithms, scripting, and entire process chains. Focusing on a remote sensing-based derivation of land use by using additional existing information on land use (e.g., from stand maps or forest inventories), can substantially increase the degree of automation for forest mapping. Additionally, newer information and information provided within shorter timespans on the extent of woodland/forest areas by NFls-which combine terrestrial sampling with remotely sensed estimations - may be used with positive results. 
With a higher degree of automation, high-quality forest maps based on remote sensing can be

934 derived more frequently and help provide the latest information on forest resources for entire countries

935 and continents in the future. In turn, retrospective analysis of changes in these areas will become

936 feasible and increasing interest will lead to the development of wall-to-wall forest maps that will

937 become standard in many countries. While future NFIs will be based on both terrestrial surveys and

938 remotely sensed parameter estimations, mapped forest area will play a key role. It is expected that the

939 future of NFIs will be characterized by a complementary combination of diverse types of information

940 and sources of information, such as remotely sensed parameters-e.g., forest cover and trees outside

941 forest (TOF)-enquiries by the local forest service, stereo-image interpretation, and, of course,

942 terrestrial information.

\section{References}

945 Alford J (1993) Towards a new public management model: beyond "managerialism" and its critics. Aust J 946 Publ Admin 52(2):135-148

947 APEX (2011) Airborne Prism Experiment. http://www.apex-esa.org Accessed 28 March 2016

948 Baatz M, Schäpe A (2000) Multiresolution Segmentation - an optimization approach for high quality 949 multi-scale image segmentation. In: Strobl J, Blaschke T, Griesebner G (eds) Angewandte Geographische 950 Informationsverarbeitung XII. Beiträge zum AGIT Symposium, Wichmann, Heidelberg, Germany, pp 1295123

952 Barrett F, McRoberts RE, Tomppo E, Cienciala E, Waser LT (2016) A questionnaire-based review of the 953 operational use of remotely sensed data by national forest inventories. Remote Sens Environ, 174:279954289

955 Bartholomé E, Belward AS (2005) GLC2000: a new approach to global land cover mapping from Earth 956 observation data. Int J Remote Sens (26):1959-1977

957 Brandtberg T (2002) Individual tree-based species classification in high spatial resolution aerial images of 958 forests using fuzzy sets. Fuzzy Set Sys 132(3):371-387

959 Chen JM, Leblanc S (1997) A four-scale bidirectional reflectance model based on canopy architecture. 960 IEEE T Geosci Remote 35:1316-1337

961 Cheng YZ (1995) Mean Shift, Mode Seeking, and Clustering. IEEE T Pattern Anal 17: 790-799

962 Chubey M, Stehle K, Albricht R, Gougeon F, Leckie D, Gray S, Woods M, Courville P (2009) Semi963 Automated Species Classification in Ontario Great Lakes - St. Lawrence Forest Conditions. Final Report: 964 Great Lakes - St. Lawrence ITC Project (2005/2008). Ontario Ministry of Natural Resources, January $965 \quad 2009$, p 71 
Dalponte M, Orka HO, Ene LT, Gobakken T, Naesset E (2014) Tree crown delineation and tree species classification in boreal forests using hyperspectral and ALS data. Remote Sens Environ 140:306-317

Darvishsefat A, Kellenberger T, Itten K (2002) Application of hyperspectral data for forest stand mapping. Int Arch Photogram Rem Sens Spatial Inform Sci 34 (4)

Dees M, Koch B, Pelz D (1998) Integrating satellite based forest mapping with Landsat TM in a concept of a large scale forest information system. PFG 4:209-220

Dong J, Xiao X, Sheldon S, Biradar C, Zhang G, Dinh Duong N, et al. (2014) A 50-m Forest Cover Map in Southeast Asia from ALOS/PALSAR and Its Application on Forest Fragmentation Assessment. PLoS ONE 9(1): e85801. doi:10.1371/journal.pone.0085801

Edelsbrunner H (1995) Smooth surfaces for multi-scale shape representation. Lecture Notes in Computer Science 1026:391-412

Eysn L, Hollaus M, Schadauer K, Pfeifer N (2012) Forest delineation based on airborne LiDAR data. Remote Sens 4:762-783

Eysn L, Hollaus M, Lindberg E, Berger F, Monnet J, Dalponte M, Kobal M, Pellegrini M, Lingua E, Mongus D, Pfeifer N (2015) A Benchmark of Lidar-Based Single Tree Detection Methods Using Heterogeneous Forest Data from the Alpine Space. Forests 6:1721-1747

FAO (1997) Food and Agriculture Organization. State of the World's Forests. Food and Agriculture Organization, Rome, Italy, 200 pp

FAO (1999) Food and Agriculture Organization. UNEP Terminology for Integrated Resources Planning and Management. Food and Agriculture Organization/United nations Environmental Program, Rome, Italy and Nairobi, Kenia

FAO (2000) Food and Agriculture Organization. FRA 2000: On definitions of forest and forest change. Working paper 33, Forest Resource Assessment, Rome, $14 \mathrm{p}$

FAO (2001) Food and Agriculture Organization. Global Forest Resources Assessment 2000 Main Report. FAO Forestry Paper 140. FAO, Rome, Italy

FAO (2010) Food and Agriculture Organization. Global Forest Resources Assessment 2010 Main Report. FAO Forestry Paper163, Rome

FAO (2012) Food and Agriculture Organization. Global forest land-use change 1990-2005. FAO Forestry Paper 2012, Rome

Fisher P, Comber A, Wadsworth R (2005) Land Use and Land Cover: Contradiction or Complement. In: P Fisher P, DJ Unwin DJ (eds) Re-presenting GIS, Wiley, pp 199-209

Förster M, Kleinschmit B, Walentwoski H (2005) Monitoring NATURA 2000 forest habitats in Bavaria by the use of ASTER, SPOT5 and GIS data - an integrated approach. In: Proceedings of the ForestSAT 2005 conference, 31th May $-2^{\text {nd }}$ June 2005, Borås, Sweden

Förster M, Kleinschmit B (2008) Object-based classification of QuickBird data using ancillary information for the detection of forest types and NATURA 2000 habitats. In: Blaschke T, Lang S, Hay G. (eds) ObjectBased Image Analysis, Springer, pp 275-290 
1003

1004

1005

1006

1007

1008

1009

1010

1011

1012

1013

1014

1015

1016

1017

1018

1019

1020

1021

1022

1023

1024

1025

1026

1027

1028

1029

1030

1031

1032

1033

1034

1035

1036

1037

Fransson JES, Magnusson M, Folkesson K, Hallberg B, Sandberg G, Smith-Jonforsen G, Gustavsson A, Ulander LMH (2007) Mapping of wind-thrown forests using VHF/UHF SAR images. In: Proceedings of the Geoscience and Remote Sensing Symposium, IGARSS 2007, 23-28th July 2007, Barcelona, Spain, pp 2350-2353

Fukunaga K, Hostetler LD (1975) Estimation of Gradient of a Density-Function, with Applications in Pattern-Recognition. IEEE Trans Inform Theory 21:32-40

Garcia-Haro FJ, Sommer S (2002) A fast canopy reflectance model to simulate realistic remote sensing scenarios. Remote Sens Environ 81(2-3):205-227

Gebhardt S, Wehrmann T, Ruiz M, Maeda P, Bishop J, Schramm M, Kopeinig R, Cartus O, Kellndorfer J, Ressl R et al. (2014) MAD-MEX: Automatic wall-to-wall land cover monitoring for the Mexican REDDMRV program using all Landsat data. Remote Sens (6):3923-3943

Gerard F (2003) Single angle, dual angle and multi-temporal viewing: assessing through modelling the implications for forest structure variable extraction. Int J Remote Sens 24(6):1317-1334

Gerard FF, North, PRJ (1997) Analyzing the effect of structural variability and canopy gaps on forest BRDF using a geometric-optical model. Remote Sens Environ 62(1):42-62

Gillis M, Leckie D (1996) Forest inventory update in Canada. Forest Chron 72(2):138-156

GFW

The

Global

Forest

Watch. http://www.globalforestwatch.org/map/3/15.00/27.00/ALL/grayscale/loss,forestgain?begin=2001-0101\&end=2015-01-01\&threshold=30 Accessed 28 March 2016

Ginzler C, Hobi M (2015) Countrywide stereo-image matching for updating digital surface models in the framework of the Swiss national forest inventory. Remote Sens 7:4343-4370

Hansen MC, Potapov PV, Moore R, Hancher M, Turubanova SA, Tyukavina A, Thau D, Stehman SV, Goetz SJ, Loveland TR, Kommareddy A, Egorov A, Chini L, Justice CO, Townshend JRG (2013) High-Resolution Global Maps of 21st-Century Forest Cover Change. Science 342(6160):850-853

Hajnsek I, Kugler F, Lee SK, Papathanassiou KP (2009) Tropical-Forest-Parameter Estimation by means of Pol-InSAR: The INDREX II Campaign. IEEE T Geosci Remote 47(2):81-493

Hirschmugl M, Weninger B, Raggam H, Schardt M (2007) Single Tree Detection in Very High Resolution Remote Sensing Data. Remote Sens Environ 110(4):533-544

Hirschmüller H (2008) Stereo Processing by Semi-Global Matching and Mutual Information. IEEE T Pattern Anal 30(2):328-341

Hosmer DW, Lemeshow S (2000) Applied logistic regression, 2nd edition, Wiley, New York

Immitzer M, Atzberger C, Koukal, T (2012) Tree Species Classification with Random Forest Using Very High Spatial Resolution 8-Band WorldView-2 Satellite Data. Remote Sens 4(9):2661-2693

JAXA (2016) World's First High-Resolution Global Forest/Non-Forest Map. http://global.jaxa.jp/article/special/geo/shimada_e.html Accessed 28 March 2016 
1038

1039

1040

1041

1042

1043

1044

1045

1046

1047

1048

1049

1050

1051

1052

1053

1054

1055

1056

1057

1058

1059

1060

1061

1062

1063

1064

1065

1066

1067

1068

1069

1070

1071

1072

1073

Jensen JR (2005) Introductory digital image processing: A remote sensing perspective. Prentice Hall, Upper Saddle River, New York

JRC (2016) European Joint Research Center JRC. http://forest.jrc.ec.europa.eu/activities/forestmapping/forest-cover-map-2006/ Accessed 28 March 2016

Kaartinen H, Hyyppä J, Yu X, Vastaranta M, Hyyppä H, Kukko A, Holopainen M, Heipke C, Hirschmugl M, Morsdorf F, Næsset E, Pitkänen J, Popescu S, Solberg S, Wolf BM, Wu J-C (2012) An International Comparison of Individual Tree Detection and Extraction Using Airborne Laser Scanning. Remote Sens 4(4):950-974

Kaartinen H, Hyyppä J (2008) EuroSDR/ISPRS Project, Commission II "Tree Extraction" Final Report. EuroSDR (European Spatial Data Research): Dublin, Ireland, 2008

Keil M, Schardt M, Schurek A, Winter R (1990) Untersuchung und Kartierung von Waldschäden mit Methoden der Fernerkundung. DLR-Abschlussdokumentation, Kapitel Auswertung von Satellitendaten, pp 71-131

Kennedy P, Bertolo F (2002) Mapping sub-pixel forest cover in Europe using AVHRR data and national and regional statistics. Can J Remote Sens 28(2):302-321

Koch B, Dees M, van Brusselen J, Eriksson L, Fransson J, Gallaun H, Leblon B, McRoberts RE, Nilsson M, Schardt M, Seitz R, Waser LT (2008) Forestry applications. In: Li Z, Chen J, Baltsavias E (eds) Advances in Photogrammetry, Remote Sensing and Spatial Information - ISPRS 2008 Congress Book, Taylor \& Francis Group, London, pp 439-468

Koch B, Straub C, Dees M, Wang, Weinacker H (2009) Airborne laser data for stand delineation and information extraction. Int J Remote Sens 30(4):935-963

Kuusk A, Nilson T (2000) A directional multispectral forest reflectance model. Remote Sen Environ 72(2):244-252

Lamonaca A, Corona P, Barbati A (2008) Exploring forest structural complexity by multi-scale segmentation of VHR imagery. Remote Sens Environ 112(6):2839-2849

Laliberte AS, Rango A, Havstad KM, Paris JF, Beck RF, McNeely R (2004) Object-oriented image analysis for mapping shrub encroachment from 1937 to 2003 in southern New Mexico. Remote Sens Environ 93(1-2):198-210

Leckie DG, Gougeon FA, Walsworth N, Paradine D (2003) Stand delineation and composition estimation using semi-automated individual tree crown analysis. Remote Sens Environ 85(3):355-369

Leckie DG, Tinis S, Nelson T, Burnett Ch, Gougeon FA, Cloney E, Paradine D (2005) Issues in species classification of trees in old growth conifer stands. Can J Remote Sens 31(2):175-190

Lindberg E, Hollaus M (2012) Comparison of Methods for Estimation of Stem Volume, Stem Number and Basal Area from Airborne Laser Scanning Data in a Hemi-Boreal Forest. Remote Sens 4(4):1004-1023

Li XW, Strahler AH (1992) Geometric-Optical Bidirectional Reflectance Modeling of the Discrete Crown Vegetation Canopy - Effect of Crown Shape and Mutual Shadowing. IEEE T Geosci Remote 30(2):276-292 
1074 Li XW, Strahler AH, Woodcock CE (1995) A hybrid geometric optical-radiative transfer approach for 1075 modeling albedo and directional reflectance of discontinuous canopies. IEEE Trans Geosci Remote 1076 33:466-480

1077 Lund, H.G. rev*. Definitions of Forest, Deforestation, Afforestation, and Reforestation. Gainesville, V.A.: 1078 Forest Information Services. [Online] Note this paper has been continuously updated since 1998. DOI: 1079 10.13140/RG.2.1.2364.9760

1080 Magdon P, Fischer C, Fuchs H, Kleinn C (2014) Translating criteria of international forest definitions into 1081 remote sensing image analysis. Remote Sens Environ (149):252-262

1082 McRoberts RE, Tomppo EO (2007) Remote sensing support for national forest inventories. Remote Sens 1083 Environ 110(4):412-419

1084 McRoberts RE (2012) Satellite image-based maps: Scientific inference or pretty pictures? Remote Sens 1085 Environ 115(2):715-724

1086 McRoberts RE, Liknes GC, Domke, GM (2014) Using a remote sensing-based, percent tree cover map to 1087 enhance forest inventory estimation. Forest Ecol Manage (331):12-18

1089

Mottus, M, Sulev M, Lang M (2006) Estimation of crown volume for a geometric radiation model from detailed measurements of tree structure. Ecol Model (198):506-514 Næsset E (2007) Airborne laser scanning as a method in operational forest inventory: Status of accuracy assessments accomplished in Scandinavia. Scand J Forest Res 22(5):433-442

1092 Næsset E, Gobakken T (2005) Estimating forest growth using canopy metrics derived from airborne laser 1093 scanner data. Remote Sens Environ 96(3-4):453-465

1094 Nilson T, Peterson U (1991) A forest canopy reflectance model and a test case. Remote Sens Environ 1095 37:131-142

1096 Pekkarinen A, Reithmaier L, Strobl P (2009) Pan-European forest/non-forest mapping with Landsat ETM+ 1097 and CORINE Land Cover 2000 data. ISPRS J Photogramm 64(2): 171-183

1098 Petrie G, Walker AS (2007) Airborne digital imaging technology: A new overview. Photogramm Rec 1099 22(119):203-225

1100 Rahman M, Sumantyo J (2010) Mapping tropical forest cover and deforestation using synthetic aperture 1101 radar (SAR) images. Appl Geomat 2:113-121

1102 Reitberger J, Krzystek P, Heurich M (2006) Full-waveform analysis of small footprint airborne laser 1103 scanning data in the Bavarian forest national park for tree species classification. In: Koukal T, Schneider 1104 W. (eds) Proceedings of the International Workshop 3D Remote Sensing in Forestry, 14 -15th February 1105 2006, University of Natural Resources and Applied Life Sciences, Vienna, Austria, pp 218-228

1106 Rosenquist Å, Shimada M, Ito N, Watanabe M (2007) ALOS PALSAR: A pathfinder mission for global-scale 1107 monitoring of the environment. IEEE Trans Geosci Remote 45(11):3307-3316

1108 Rutzinger M, Pratihast AK, Elberink SO, Vosselman G (2010) Detection And Modelling Of 3D Trees From 1109 Mobile Laser Scanning Data. Int Arch Photogram Rem Sens Spatial Inform Sci 38(5), pp. 520-525 
Schepaschenko D, See L, Lesiv M, McCallum I, Fritz S, Salk C, Moltchanova E, Perger C, Schepashchenko

1111 M, Shvidenko A et al. (2015) Development of a global hybrid forest mask through the synergy of remote

1112 sensing, crowdsourcing and FAO statistics. Remote Sens Environ 162:208-220

1113 Shimada M, Itoh T, Motooka T, Watanabe M, Shiraishi T, Thapa R, Lucas R (2014) New global forest/non-

1114 forest maps from ALOS PALSAR data (2007-2010). Remote Sens Environ 155:13-31

1115 Solberg S, Naesset E, Bollandsas OM (2006) Single tree segmentation using airborne laser scanner data 1116 in a structurally heterogeneous spruce forest. Photogramm Eng Rem S 72:1369-1378

1117 Stibig HJ, Achard F, Fritz S (2004) A new forest cover map of continental southeast Asia derived from 1118 SPOT-VEGETATION satellite imagery. Appl Veg Sci 7(2):153-162

1119 Spurr SH (1960) Photogrammetry and photo-interpretation, 2nd edition. Ronald Press, New York

1120 Stoffels J, Mader S, Hill J, Werner W, Ontrup G (2012) Satellite-based standwise forest cover type mapping using a spatially adaptive classification approach. Eur J Forest Res 131(4):1071-1089

1122 Straub BM, Heipke, C (2001) Automatic extraction of trees for 3D city models from images and height 1123 data. Automatic Extraction of Man-Made Objects from Aerial and Space Images, 3:267-277

1124 Straub C, Weinacker H, Koch B (2008) A fully automated procedure for delineation and classification of 1125 Forest and Non-Forest Vegetation based on full-waveform Laser Scanner Data. Int Arch Photogram Rem 1126 Sens Spatial Inform Sci 37(8) pp. 1013-1019

1127 Straub C, Stepper C, Seitz R, Waser LT (2013) Potential of UltraCamX stereo images for estimating timber 1128 volume and basal area at the plot level in mixed European forests. Can J Forest Res 43(8):731-741

1129 Swisstopo (2016) The topographic landscape model TML. Available online: 1130 http://www.swisstopo.admin.ch/internet/swisstopo/en/home/topics/geodata/tlm.html Accessed 28 1131 March 2016

1132 Thiel C, Drezet P, Weise C, Quegan S, Schmullius C (2006) Radar remote sensing for the delineation of 1133 forest cover maps and the detection of deforestation. Forestry 79(5):589-597

1134 Tomppo E, Halme M (2004) Using coarse scale forest variables as ancillary information and weighting of 1135 variables in k-NN estimation: a genetic algorithm approach. Remote Sens Environ 92(1):1-20

1136 Tomppo E, Haakana M, Katila M, Peräsaari J (2008) Multi-source national forest inventory-methods and 1137

1139 Tomppo E, Gschwantner Th, Lawrence M, McRoberts RE (eds) (2010) National Forest Inventories 1140 Pathways for common reporting, $1^{\text {st }}$ edition. Springer, Berlin

1141 Vauhkonen J, Seppänen A, Packalén P, Tokola T (2012) Improving species-specific plot volume estimates 1142 based on airborne laser scanning and image data using alpha shape metrics and balanced field data. 1143 Remote Sens Environ 124: 534-541

1144 Vosselman G (2003) 3d reconstruction of roads and trees for city modeling. Int Arch Photogram Rem 1145 Sens Spatial Inform Sci 34(3), W13, Dresden, Germany, pp 231-236 
1146 Wagner W, Luckman A, Vietmeier J, Tansey K, Balzter H, Schmullius C, Davidson M, Gaveau D, Gluck M, 1147 Le Toan T, Quegan S, Shvidenko A, Wiesmann A, Yu JJ (2003) Large-scale mapping of boreal forest in 1148 SIBERIA using ERS tandem coherence and JERS backscatter data. Remote Sens Environ 85(2):125-144

1149 Wang Z, Boesch R, Ginzler C (2007.) Color and LIDAR Data Fusion: Application to automated forest 1150 boundary delineation in aerial images. Int Arch Photogram Rem Sens Spatial Inform Sci 36(1)

1151 Wang Z, Ginzler C, Waser LT (2015) A novel method to assess short-term forest cover changes based on 1152 digital surface models from image-based point clouds. Forestry (88):429-440

1153 Waser LT, Baltsavias E, Ecker K, Eisenbeiss H, Feldmeyer-Christe E, Ginzler C, Küchler M, Thee P, Zhang L 1154 (2008a) Assessing changes of forest area and shrub encroachment in a mire ecosystem using digital 1155 surface models and CIR-aerial images. Remote Sens Environ 112(5):1956-1968

1156 Waser LT, Baltsavias E, Ecker K, Eisenbeiss H, Ginzler C, Küchler M, Thee P, Zhang L (2008b) High1157 resolution digital surface models (DSM) for modeling fractional shrub/tree cover in a mire environment. 1158 Int J Remote Sens 29(5):1261-1276

1159 Waser LT, Klonus S, Ehlers M, Küchler M, Jung A (2010) Potential of Digital Sensors for Land Cover and 1160 Tree Species Classifications - A Case Study in the Framework of the DGPF-Project. PFG 2:141-156

1161 Waser LT, Ginzler C, Kuechler M, Baltsavias E, Hurni L, (2011) Semi-automatic classification of tree 1162 species in different forest ecosystems by spectral and geometric variables derived from Airborne Digital 1163 Sensor (ADS40) and RC30 data. Remote Sens Environ 115(1):76-85

1164 Waser LT (2012) Airborne remote sensing data for semi-automated extraction of tree area and 1165 classification of tree species. Dissertation, ETH Zürich, 153 p. $\underline{\text { http://e- }}$ 1166 collection.library.ethz.ch/view/eth:6087

1167 Waser LT, Küchler M, Jütte K, Stampfer T (2014) Evaluating the Potential of WorldView-2 Data to Classify 1168 Tree Species and Different Levels of Ash Mortality. Remote Sens (6):4515-4545

1169 Waser LT, Fischer C, Wang Z, Ginzler C (2015) Wall-to-Wall Forest Mapping Based on Digital Surface 1170 Models from Image-Based Point Clouds and a NFI Forest Definition. Forests 6:4510-4528

1171 Zeverbergen, LW, and C. R. Thorne, LW (1987) Quantitative Analysis of Land Surface Topography. Earth 1172 Surf Processes 12:47-56

1173

1174 